Supporting Information for

\title{
Comparative Study of the Limitations and Challenges in Atom-Transfer $\mathrm{C}-\mathrm{H}$ Oxidations
}

\author{
Ashley M. Adams ${ }^{\dagger}$, J. Du Bois ${ }^{\dagger}$, and Hasnain A. Malik ${ }^{\ddagger *}$ \\ † Department of Chemistry, Stanford University, Stanford, CA 94305, USA \\ ‡ Department of Global Discovery Chemistry, Novartis Institutes for BioMedical Research, Inc., 100 \\ Technology Square, Cambridge, MA 02139, USA
}




\section{General Experimental Details}

Unless otherwise noted, all reactions were conducted under ambient conditions with magnetic stirring. Acetic acid (Sigma Aldrich), Mn(OTf) ${ }_{2}$ (Sigma Aldrich), and 2,2'bipyridine (Alfa Aesar) were used as received and transfer under ambient atmosphere. Peracetic acid (Sigma Aldrich), Fe-(S,S-PDP) (Strem), and $\mathrm{AgClO}_{4}$ (Strem) were used as received and stored at $4{ }^{\circ} \mathrm{C}$. Mn-(S,S-PDP) was synthesized following known procedures and was stored under nitrogen at $4{ }^{\circ} \mathrm{C} .{ }^{1}$

Chromatographic purification of products was accomplished using forced flow chromatography on Kieselgel 60 (230-400 mesh) silica gel. Thin layer chromatography was performed on Kieselgel silica gel 60 F254 plates $(250 \mu \mathrm{m})$. Visualization of the developed chromatogram was accomplished by fluorescence quenching and by staining with ethanolic anisaldehyde, aqueous potassium permanganate, or aqueous ceric ammonium molybdate (CAM) solution.

${ }^{1} \mathrm{H}$ NMR spectra were measured at $400 \mathrm{MHz}$ on a Bruker Avance instrument and are referenced internally according to residual solvent signals $\left(\delta 7.26\right.$ for $\left.\mathrm{CHCl}_{3}\right)$. For quantitative NMR analyses, the delay time was set to 30 seconds $(\mathrm{d} 1=30)$ and the number of scans was set to $16(\mathrm{nt}=16) .{ }^{2}{ }^{13} \mathrm{C}$ NMR spectra were recorded at $100 \mathrm{MHz}$ in ${ }^{1} \mathrm{H}$ and heteroatom-decoupled mode. The signal from residual chloroform $(\delta 77.0)$ was used as an internal reference. Infrared (IR) spectra were recorded as thin films using $\mathrm{NaCl}$ plates on a Thermo-Nicolet 300 FT-IR spectrometer and are reported in frequency of absorption. High resolution mass spectra were obtained from the Vincent Coates Foundation Mass Spectrometry Laboratory at Stanford University.

1. Ottenbacher, R. V.; Samsonenko, D. G.; Talsi, E. P.; Bryliakov, K. P. Highly efficient, regioselective, and stereospecific oxidation of aliphatic $\mathrm{C}-\mathrm{H}$ groups with $\mathrm{H}_{2} \mathrm{O}_{2}$, catalyzed by aminopyridine manganese complexes. Org. Lett. 2012, 14, 4310-4313.

2. Maniara, G.; Rajamoorthi, K.; Rajan, S.; Stockton, G. Method Performance and Validation for Quantitative Analysis by ${ }^{1} \mathrm{H}$ and ${ }^{31} \mathrm{P}$ NMR Spectroscopy. Applications to Analytical Standards and Agricultural Chemicals. Anal. Chem., 1998, 70, 4921-4928. 
Figure S.1. Hydroxylation Methods in Total Synthesis and State-of-the-art

\section{Methods.}
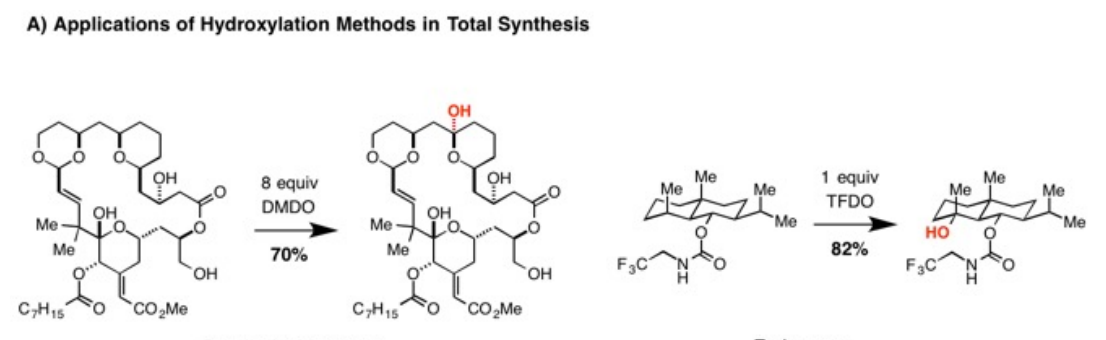

Bryostatin Analogues

Eudesmane

Terpenoids
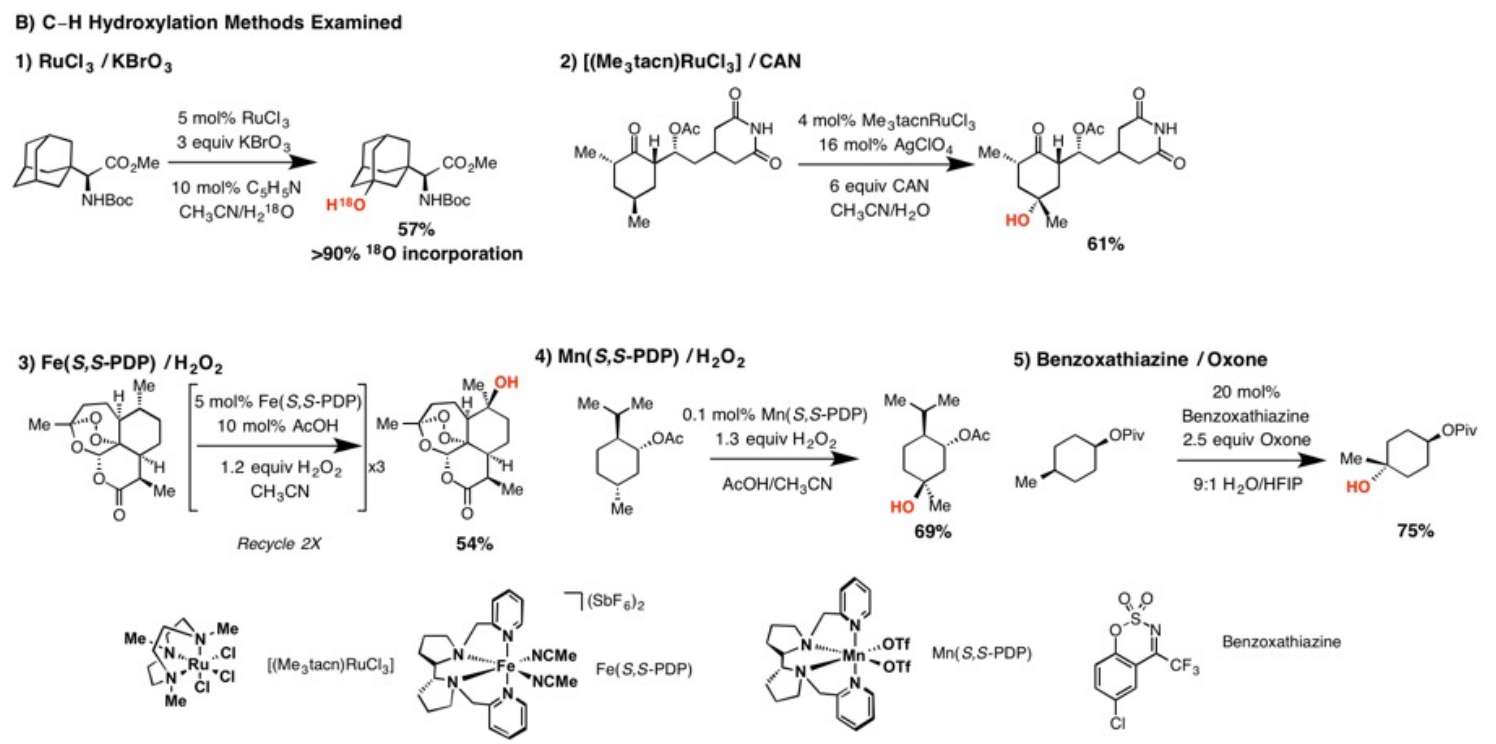

\section{Development of a Manganese System for $\mathbf{C}-\mathbf{H}$ hydroxylation}

\section{Screening Protocol}

Stock solutions were synthesized as follows: A $12.5 \mathrm{mM}$ solution of $\mathrm{Mn}(\mathrm{OTf})_{2}$ was prepared by dissolving $4.4 \mathrm{mg}$ of $\mathrm{Mn}(\mathrm{OTf})_{2}$ in $1.0 \mathrm{~mL}$ of a 9:1 $\mathrm{AcOH} / \mathrm{H}_{2} \mathrm{O}$ mixture. A $0.025 \mathrm{M}$ solution of ligand was prepared by dissolving ligand in $1.0 \mathrm{~mL}$ of $\mathrm{AcOH}$.

Modified commercial peracetic acid (PAA $\left.\mathrm{CM}_{\mathrm{CM}}\right)$ was prepared by addition $10 \% \mathrm{KOH}(0.3$ $\mathrm{mL})$ to $35 \%$ peracetic acid in $\mathrm{AcOH}(1.0 \mathrm{~mL})$.

To a 20 dram vial containing 4-methylpentyl-2,4-difluorobenzoate (24 mg, $0.10 \mathrm{mmol}$ ), AcOH $(0.48 \mathrm{~mL})$, and $\mathrm{H}_{2} \mathrm{O}(20 \mu \mathrm{L})$ was added sequentially solutions of $\mathrm{Mn}(\mathrm{OTf})_{2}(8 \mu \mathrm{L}$, 0.001 equiv) and ligand ( $40 \mu \mathrm{L}, 0.01$ equiv). The clear solution was stirred for $10 \mathrm{~min}$ before a solution of PAA $\mathrm{C}_{\mathrm{CM}}(88 \mu \mathrm{L}, 0.3 \mathrm{mmol})$ was added dropwise. Note: the addition of $\mathrm{PAA}_{\mathrm{CM}}$ results in a significant exotherm; caution should be taken. After $90 \mathrm{~s}$, the 
reaction was diluted with $10 \mathrm{~mL}$ of acetone, stirred for 30 seconds and filtered through a small pad of Celite. The flask and filter cake were rinsed with $20 \mathrm{~mL}$ of acetone, and the combined filtrates were concentrated under reduced pressure.

Table S.1. Optimization of metal-to-ligand ratio using substrate 1 .

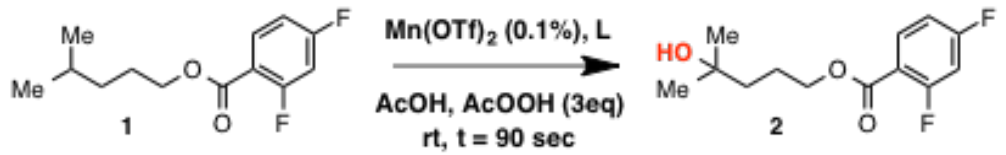

\begin{tabular}{cccc}
\hline Entry & Ligand & Ligand Loading & 1 (Conversion) $^{\mathbf{a}}$ \\
\hline $\mathbf{1}$ & Phenanthroline & $0.20 \%$ & $24(44)$ \\
$\mathbf{2}$ & Phenanthroline & $0.50 \%$ & $35(60)$ \\
$\mathbf{3}$ & Phenanthroline & $1.00 \%$ & $46(85)$ \\
$\mathbf{4}$ & Bipyridine & $0.20 \%$ & $21(35)$ \\
$\mathbf{5}$ & Bipyridine & $0.50 \%$ & $32(52)$ \\
$\mathbf{6}$ & Bipyridine & $1.00 \%$ & $43(80)$ \\
$\mathbf{7}$ & Picolinic Acid & $0.10 \%$ & $8(12)$ \\
$\mathbf{8}$ & Picolinic Acid & $0.50 \%$ & $22(38)$ \\
$\mathbf{9}$ & Picolinic Acid & $1.00 \%$ & $37(72)$ \\
$\mathbf{1 0}$ & Terpyridine & $1.00 \%$ & $37(62)$ \\
$\mathbf{1 1}$ & Terpyridine & $5.00 \%$ & $30(50)$ \\
$\mathbf{1 2}$ & None & $0.00 \%$ & $0(0)$ \\
\hline
\end{tabular}

a) Differences between formation of product 2 and percent conversion derive from methylene oxidation on the alkyl chain. Percent conversions were measured by ${ }^{19} \mathrm{~F}$ and ${ }^{1} \mathrm{H}$ NMR integrations.

\section{Reaction Protocol}

To a 20 dram vial containing substrate $(1.0 \mathrm{mmol})$, $\mathrm{AcOH}(4.8 \mathrm{~mL})$, and $\mathrm{H}_{2} \mathrm{O}(0.2 \mathrm{~mL})$ was added solid $\mathrm{Mn}(\mathrm{OTf})_{2}$ (0.3 mg, $1.0 \mu \mathrm{mol}, 0.001$ equiv), and bipyridine (1.6 mg, 1.0 $\mu \mathrm{mol}, 0.01$ equiv). After stirring for $10 \mathrm{~min}$, PAA $\mathrm{CM}_{\mathrm{CM}}$ solution $(0.88 \mathrm{~mL}, 3.6 \mathrm{M}, 3.0$ equiv) was added dropwise over $90 \mathrm{~s}$. After an additional $90 \mathrm{~s}$ of stirring, the reaction mixture was diluted with $10 \mathrm{~mL}$ of EtOAc and transferred to a separatory funnel containing $20 \mathrm{~mL}$ of saturated aqueous $\mathrm{Na}_{2} \mathrm{~S}_{2} \mathrm{O}_{3}$. The organic layer was collected and the aqueous layer was extracted with 2 x $20 \mathrm{~mL}$ with EtOAc. The combined organic extracts were washed with $15 \mathrm{~mL}$ of $\mathrm{H}_{2} \mathrm{O}$ and $15 \mathrm{~mL}$ of saturated aqueous $\mathrm{NaCl}$, dried over 
$\mathrm{Na}_{2} \mathrm{SO}_{4}$, filtered, and concentrated under reduced pressure. Purification of this material by chromatography on silica gel (conditions given below) afforded the desired product.

Table S.1. Substrate scope of the manganese catalyzed C-H oxidation reaction.

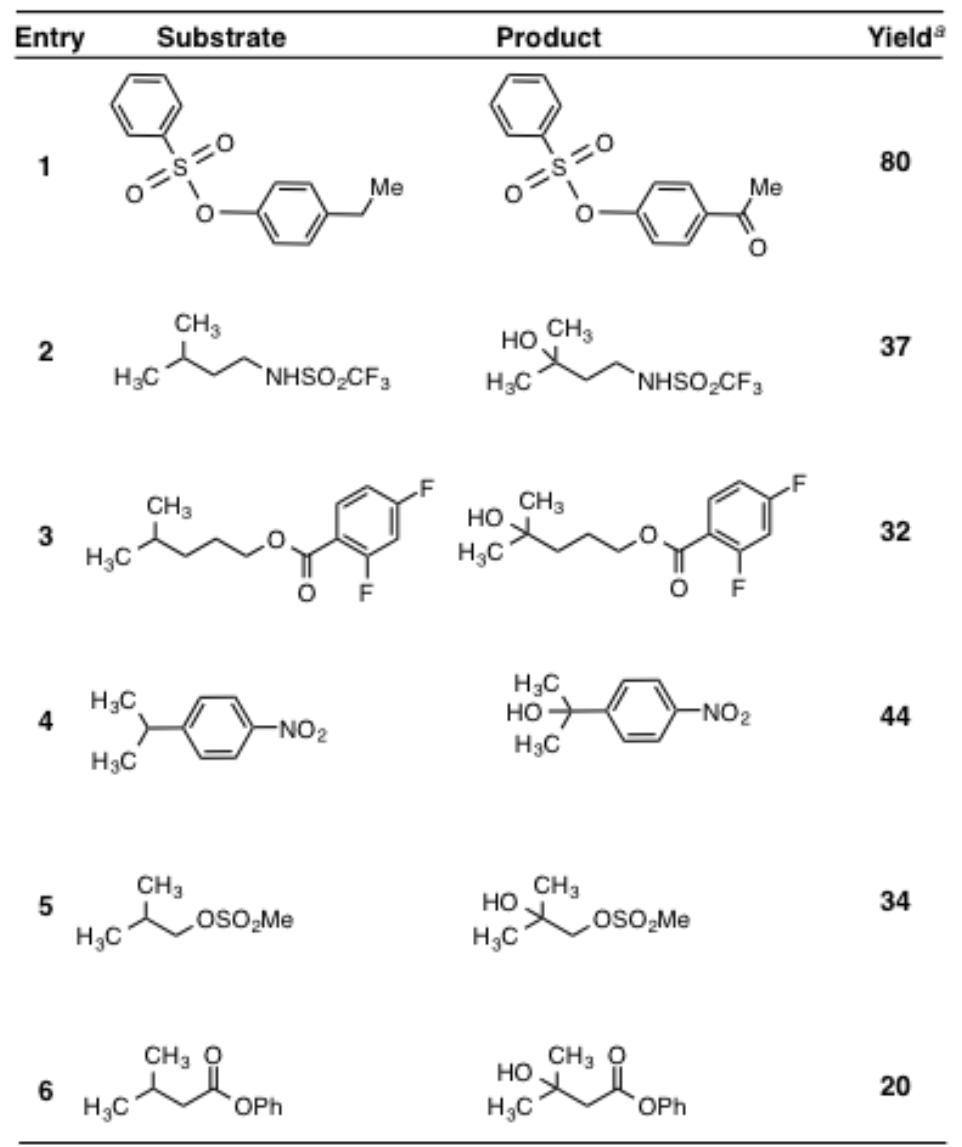

a) Reaction conducted on a $1 \mathrm{mmol}$ scale with $\mathrm{Mn}(\mathrm{OTf})_{2}(0.1 \%)$, bipyridine (1\%), $\mathrm{AcOOH}$ (3.0 eq), $\mathrm{AcOH}, 90$ seconds.

\section{Comparative Reaction Screening}

\section{Screening Reaction Protocols}

All reactions were conducted on a $0.25 \mathrm{mmol}$ scale. After drying all reactions to remove any residual solvent, pyrazine (10 $\mathrm{mg}, 0.125 \mathrm{mmol}$ ) was added to each reaction. The mixture was dissolved in deuterated solvent and analyzed by ${ }^{1} \mathrm{H}$ NMR.

$\mathrm{RuCl} \mathrm{Cl}_{3}$-catalyzed oxidation

A 20 dram vial was charged with $\mathrm{RuCl}_{3} \cdot \mathrm{H}_{2} \mathrm{O}$ (2.6 mg, $12.5 \mu$ mol, 0.05 equiv) and $\mathrm{KBrO}_{3}$ (125 mg, $0.75 \mathrm{mmol}$, 3.0 equiv). To this mixture was added $2.0 \mathrm{~mL}$ of $\mathrm{H}_{2} \mathrm{O}$ and pyridine 
(2.0 $\mu \mathrm{L}, 25.0 \mu \mathrm{mol}, 0.10$ equiv), followed by a solution of substrate $(0.25 \mathrm{mmol})$ in 2.0 $\mathrm{mL}$ of $\mathrm{CH}_{3} \mathrm{CN}$. The pale yellow solution was stirred at $60^{\circ} \mathrm{C}$ for $24 \mathrm{~h}$. Following this time, the reaction mixture was quenched with $2 \mathrm{~mL}$ of saturated aqueous $\mathrm{Na}_{2} \mathrm{~S}_{2} \mathrm{O}_{3}$ and the contents transferred to a separatory funnel with $30 \mathrm{~mL}$ of $\mathrm{H}_{2} \mathrm{O}$. The aqueous mixture was extracted with 3 x $25 \mathrm{~mL}$ of EtOAc. The combined organic fractions were washed 1 x 25 $\mathrm{mL}$ of saturated aqueous $\mathrm{NaCl}$, dried over $\mathrm{MgSO}_{4}$, filtered, and concentrated under reduced pressure.

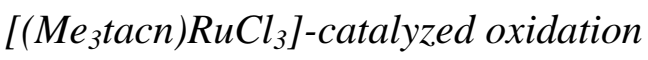

A 20 dram vial was charged with [(Me $\left.\left.\mathrm{Mecn}_{3}\right) \mathrm{RuCl}_{3}\right]$ (2 mg, $5.0 \mu \mathrm{mol}, 0.02$ equiv), $\mathrm{AgClO}_{4}$ (4 mg, $0.02 \mathrm{mmol}, 0.08$ equiv), and $2.0 \mathrm{~mL}$ of $\mathrm{H}_{2} \mathrm{O}$. The mixture was stirred at $80{ }^{\circ} \mathrm{C}$ for 5 min during which time $\mathrm{AgCl}$ precipitation was observed. After cooling the solution to ambient temperature, a solution of substrate $(0.25 \mathrm{mmol})$ in $2.0 \mathrm{~mL}$ of tertbutanol was added, followed by ceric ammonium nitrate ( $411 \mathrm{mg}, 0.75 \mathrm{mmol}, 3.0$ equiv). This mixture was stirred for 15 min following which time an additional $411 \mathrm{mg}$ of ceric ammonium nitrate was added. The reaction was stirred for and additional $4 \mathrm{~h}$ prior to being quenched with $1 \mathrm{~mL}$ of $\mathrm{MeOH}$. The resulting yellow solution was transferred to a separatory funnel containing $30 \mathrm{~mL}$ of $\mathrm{H}_{2} \mathrm{O}$. The aqueous mixture was extracted with $2 \mathrm{x}$ $25 \mathrm{~mL}$ of EtOAc. The combined organic fractions were washed with $25 \mathrm{~mL}$ of $\mathrm{H}_{2} \mathrm{O}$ and $25 \mathrm{~mL}$ of saturated aqueous $\mathrm{NaCl}$, dried over $\mathrm{MgSO}_{4}$, filtered and concentrated under reduced pressure.

\section{$\mathrm{Mn}(\mathrm{OTf})_{2} /$ bipyridine-catalyzed oxidation}

A $12.5 \mathrm{mM}$ solution of $\mathrm{Mn}(\mathrm{OTf})_{2}$ was prepared by dissolving $4.4 \mathrm{mg}$ of $\mathrm{Mn}(\mathrm{OTf})_{2}$ in 1.0 $\mathrm{mL}$ of a 9:1 AcOH$/ \mathrm{H}_{2} \mathrm{O}$ solution. A $0.025 \mathrm{M}$ solution of 2,2'-bipyridine was prepared by dissolving $3.9 \mathrm{mg}$ of bipyridine in $1.0 \mathrm{~mL}$ of $\mathrm{AcOH}$.

Modified commercial peracetic acid was prepared by mixing $1.0 \mathrm{~mL}$ of commercial peracetic acid solution (35\% Aldrich) with $0.3 \mathrm{~mL}$ of $10 \% \mathrm{KOH}$ solution.

To a 20 dram reaction vial with containing substrate $(0.25 \mathrm{mmol})$ was added $1.25 \mathrm{~mL}$ of $\mathrm{AcOH}$, followed by solutions of $\mathrm{Mn}(\mathrm{OTf})_{2}(20 \mu \mathrm{L}, 0.25 \mu \mathrm{mol}, 0.001$ equiv) and bipyridine (100 $\mu \mathrm{L}, 2.5 \mu \mathrm{mol}, 0.01$ equiv). The colorless mixture was stirred for $10 \mathrm{~min}$ 
prior to the dropwise addition (30 s) of a solution of $\mathrm{PAA}_{\mathrm{CM}}(220 \mu \mathrm{L}, 0.75 \mathrm{mmol}, 3.0$ equiv). Note: the addition of $\mathrm{PAA}_{\mathrm{CM}}$ results in a significant exotherm; caution should be taken. After $60 \mathrm{~s}$, the reaction was diluted with $5 \mathrm{~mL}$ of acetone and stirred for 30 seconds and filtered through a small pad of Celite. The flask and filter cake were rinsed with $\sim 25 \mathrm{~mL}$ of acetone, and the combined filtrates were concentrated under reduced pressure.

Mn-(S,S-PDP)-catalyzed oxidation

A $5.0 \mathrm{mM}$ solution of Mn-(S,S-PDP) was prepared by dissolving $3.4 \mathrm{mg}$ of catalyst in 1.0 $\mathrm{mL}$ of $\mathrm{CH}_{3} \mathrm{CN}$.

A $7 \mathrm{~mL}$ vial was charged with substrate $(0.25 \mathrm{mmol}), 950 \mu \mathrm{L}$ of $\mathrm{CH}_{3} \mathrm{CN}$, and $\mathrm{AcOH}$ (200 $\mu \mathrm{L}, 3.5 \mathrm{mmol}$, 14.0 equiv). To this mixture was added Mn-(S,S-PDP) catalyst solution (50 $\mu \mathrm{L}, 0.25 \mu \mathrm{mol}, 0.001$ equiv). The colorless solution was cooled to $0{ }^{\circ} \mathrm{C}$ and an solution of $\mathrm{H}_{2} \mathrm{O}_{2}$ ( $35 \mathrm{wt} \%, 28 \mu \mathrm{L}, 0.325 \mathrm{mmol}, 1.3$ equiv) in $250 \mu \mathrm{L}$ of $\mathrm{CH}_{3} \mathrm{CN}$ was added dropwise over $1 \mathrm{~h}$. Upon addition of $\mathrm{H}_{2} \mathrm{O}_{2}$, the solution changes to a pale yellow color that persists for the entirety of the reaction. The reaction was stirred at $0{ }^{\circ} \mathrm{C}$ for an additional $1 \mathrm{~h}$. Following this time, the reaction was quenched with $3 \mathrm{~mL}$ of aqueous $\mathrm{NaHCO}_{3}$. The solution was transferred to a separatory funnel with $10 \mathrm{~mL}$ of EtOAc. The organic phase was collected and the aqueous layer was extracted with $2 \times 20 \mathrm{~mL}$ of EtOAc. The combined organic fractions were washed with $25 \mathrm{~mL}$ of $\mathrm{H}_{2} \mathrm{O}$ and $25 \mathrm{~mL}$ of saturated aqueous $\mathrm{NaCl}$, dried over $\mathrm{MgSO}_{4}$, filtered and concentrated under reduced pressure.

\section{$\mathrm{Fe}-(\mathrm{S}, \mathrm{S}-\mathrm{PDP})$-catalyzed oxidation}

In two separate vials, solutions containing Fe-(S,S-PDP) (12 mg, $12.5 \mu \mathrm{mol}, 0.05$ equiv), AcOH (7.5 mg, 0.125 mmol, 0.5 equiv) in $250 \mu \mathrm{L}$ of $\mathrm{CH}_{3} \mathrm{CN}$ were prepared.

A 20 dram vial was charged with Fe-(S,S-PDP) (12 mg, $12.5 \mu \mathrm{mol}, 0.05$ equiv), substrate (0.25 mmol), AcOH (7.5 mg, $0.125 \mathrm{mmol}, 0.5$ equiv), and $375 \mu \mathrm{L}$ of $\mathrm{CH}_{3} \mathrm{CN}$. To this dark purple mixture was added dropwise (45 s) a solution of $\mathrm{H}_{2} \mathrm{O}_{2}$ (50 wt\%, 18.4 $\mu \mathrm{L}, 0.3 \mathrm{mmol}, 1.2$ equiv) in $2.25 \mathrm{~mL}$. After stirring for $10 \mathrm{~min}$, an aliquot $(250 \mu \mathrm{L})$ of the Fe-(S,S-PDP) solution was added dropwise. This was followed by the dropwise 
addition (45 s) of a solution of $\mathrm{H}_{2} \mathrm{O}_{2}$ (50 wt\%, $18.4 \mu \mathrm{L}, 0.3 \mathrm{mmol}, 1.2$ equiv) in $2.25 \mathrm{~mL}$ of $\mathrm{CH}_{3} \mathrm{CN}$. Following another 10 min period, this process was repeated with the second aliquot of the Fe-(S,S-PDP) mixture. After stirring for an additional $10 \mathrm{~min}$, the dark amber solution was concentrated under reduced pressure to a volume of $\sim 1 \mathrm{~mL}$, diluted with $20 \mathrm{~mL}$ of $\mathrm{Et}_{2} \mathrm{O}$, and filtered through a small pad of Celite. The flask and filter cake were rinsed with $\sim 20 \mathrm{~mL}$ of $\mathrm{Et}_{2} \mathrm{O}$ and the filtrate concentrated under reduced pressure to an oily residue. To remove residual $\mathrm{AcOH}$, the unpurified product was dissolved in 20 $\mathrm{mL}$ of $\mathrm{Et}_{2} \mathrm{O}$ and filtered through a Supelco bicarbonate column. The flask and filter were rinsed with $\sim 50 \mathrm{~mL}$ of $\mathrm{Et}_{2} \mathrm{O}$ and the filtrate and concentrated under reduced pressure.

\section{Benzoxathiazine-catalyzed oxidation}

To a $7 \mathrm{~mL}$ screwtop vial was added substrate $(0.25 \mathrm{mmol})$, benzoxathiazine catalyst (14 mg, $0.05 \mathrm{mmol}, 0.2$ equiv), Oxone (192 mg, 2.5 equiv, $0.625 \mathrm{mmol}), 100 \mu \mathrm{L}$ of HFIP and $900 \mu \mathrm{L}$ of $\mathrm{H}_{2} \mathrm{O}$. The vial was sealed and the reaction mixture was stirred at $70{ }^{\circ} \mathrm{C}$ for 12 or $24 \mathrm{~h}$. Following this time, the solution was cooled to ambient temperature and transferred to a separatory funnel with $15 \mathrm{~mL}$ of EtOAc and $25 \mathrm{~mL}$ of $\mathrm{H}_{2} \mathrm{O}$. The organic layer was collected and the aqueous phased was extracted with 2 x by $25 \mathrm{~mL}$ of EtOAc. The combined organic extracts were dried over $\mathrm{MgSO}_{4}$, filtered, and concentrated under reduced pressure.

\subsubsection{Protocols for oxidation of pyridyl substrates.}

[(Me 3 tacn) $\left.\mathrm{RuCl}_{3}\right]: \quad$ A 20 dram vial was charged with [( $\left.\left.\mathrm{Me}_{3} \mathrm{tacn}\right) \mathrm{RuCl}_{3}\right]$ (4 mg, 10.0 $\mu \mathrm{mol}, 0.02$ equiv), $\mathrm{AgClO}_{4}$ (8 mg, $40 \mu \mathrm{mol}, 0.08$ equiv), and $4.0 \mathrm{~mL}$ of $\mathrm{H}_{2} \mathrm{O}$. The mixture was stirred at $80{ }^{\circ} \mathrm{C}$ for 5 min during which time AgCl precipitation was observed. After cooling the reaction to room temperature, a solution of substrate $(0.5$ $\mathrm{mmol}$ ) in $4.0 \mathrm{~mL}$ of $t-\mathrm{BuOH}$ was added, followed by portionwise addition of solid ceric ammonium nitrate (822 mg, $1.5 \mathrm{mmol}, 3.0$ equiv). This orange mixture was stirred for 15 min following which time an additional $822 \mathrm{mg}$ of ceric ammonium nitrate was added. The dark brown reaction mixture was stirred for $4 \mathrm{~h}$ then quenched with the addition of 1 $\mathrm{mL}$ of $\mathrm{MeOH}$. The solution was transferred to a separatory funnel containing $10 \mathrm{~mL}$ of 2 $\mathrm{N} \mathrm{NaOH}$ and $30 \mathrm{~mL}$ of EtOAc. The organic phase was collected and the aqueous layer 
was extracted with $3 \times 25 \mathrm{~mL}$ of EtOAc. The combined organic extracts were washed with $20 \mathrm{~mL}$ of saturated aqueous $\mathrm{NaCl}$, dried over $\mathrm{Na}_{2} \mathrm{SO}_{4}$, filtered and concentrated under reduced pressure. Purification of this material by chromatography on silica gel (conditions given below) afforded the desired product.

$\mathrm{Mn}(\mathrm{OTf})_{2}$-bipy: To a 20 dram reaction vial containing substrate $(0.5 \mathrm{mmol})$ was added $2.4 \mathrm{~mL}$ of $\mathrm{AcOH}, 100 \mu \mathrm{L}$ of $\mathrm{H}_{2} \mathrm{O}, \mathrm{Mn}(\mathrm{OTf})_{2}(0.2 \mathrm{mg}, 0.5 \mu \mathrm{mol}, 0.001$ equiv), and bipyridine ( $0.8 \mathrm{mg}, 0.5 \mu \mathrm{mol}, 0.01$ equiv). The reaction mixture was stirred for $10 \mathrm{~min}$ prior to the dropwise addition (30 s) of a solution of PAA $\mathrm{CM}_{\mathrm{CM}}(440 \mu \mathrm{L}, 1.5 \mathrm{mmol}, 3.0$ equiv). The yellow solution was stirred for an additional $250 \mathrm{~s}$ and then diluted with 10 $\mathrm{mL}$ of acetone. The mixture was filtered through a Supelco bicarbonate column using an additional $30 \mathrm{~mL}$ of acetone to rinse the flask and filter. The filtrate was concentrated under reduced pressure to an oily residue. Purification of this material by chromatography on silica gel (conditions given below) afforded the desired product. 
Characterization of selected compounds.

$\mathrm{PhS}(\mathrm{O})_{2} \mathrm{O}-\left\langle=\mathrm{C}_{\mathrm{O}}^{\mathrm{Me}}\right.$

4-Acetylphenyl benzenesulfonate (Table 2, Product 2). ${ }^{21 \mathrm{c}}$

Purified by chromatography on silica gel using 15\% acetone/hexanes (yellow oil, $80 \%$ ).

TLC $\mathrm{R}_{f}=0.42$ (4:1 hexanes/EtOAc); ${ }^{1} \mathrm{H}$ NMR $\left(\mathrm{CDCl}_{3}, 400 \mathrm{MHz}\right) \delta$ 7.90-7.87 (m, 2H),

7.83-7.81 (m, 2H), 7.69-7.65 (m, 1H), 7.55-7.51 (m, 2H), 7.08-7.05 (m, 2H), 2.55 (s, 3H) ppm.

Me ${ }_{\mathrm{Me}}^{\mathrm{OH}} \mathrm{NHSO}_{2} \mathrm{CF}_{3}$

1,1,1-Trifluoro- $N$-(3-hydroxy-3-methylbutyl)methanesulfonamide (Table 2, Product 3). ${ }^{21 \mathrm{c}}$ Purified by chromatography on silica gel using $25 \%$ EtOAc/hexanes (pale yellow oil, 37\%). TLC $\mathrm{R}_{\mathrm{f}}=0.12\left(7: 1\right.$ hexanes/EtOAc) ${ }^{1} \mathrm{H}$ NMR $\left(\mathrm{CDCl}_{3}, 400 \mathrm{MHz}\right) \delta 6.50$ (s, 1H), 3.50 (m, 2H), 1.79-1.74 (m, 2H), 1.66 (s, 1H), 1.31 (s, 6H) ppm.

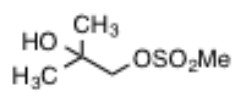

2-Hydroxy-2-methylpropyl methanesulfonate. (Table 2, Product 5)

Purified by chromatography on silica gel using $20 \%$ acetone/hexanes (yellow oil, 58mg, 34\%). TLC $R_{f}=0.64\left(20: 1 \mathrm{CH}_{2} \mathrm{Cl}_{2} / \mathrm{MeOH}\right) ;{ }^{1} \mathrm{H} \mathrm{NMR}\left(\mathrm{CDCl}_{3}, 400 \mathrm{MHz}\right) \delta 4.06(\mathrm{~s}, 2 \mathrm{H})$, 3.07 (s, 3H), 1.30 (s, 6H) ppm; ${ }^{13} \mathrm{C}$ NMR $\left(\mathrm{CDCl}_{3}, 100 \mathrm{MHz}\right) \delta$ 76.8, 69.8, 37.7, 26.0 ppm; IR (thin film) $v$ 3425, 3027, 2935, 1732, 1491, 1353, 1174, 966, $920 \mathrm{~cm}^{-1}$.

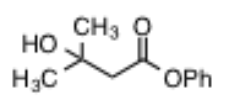

Phenyl 3-hydroxy-3-methylbutanoate. (Table S2, Product 6)

Purified by chromatography on silica gel using $15 \%$ acetone/hexanes (clear oil, 38mg, 20\%). TLC $R_{f}=0.56$ (6:1 hexanes/acetone); ${ }^{1} \mathrm{H} \mathrm{NMR}\left(\mathrm{CDCl}_{3}, 400 \mathrm{MHz}\right) \delta 7.40$ (dd, 2H, $J=9.2,7.6 \mathrm{~Hz}$ ), 7.28-7.23 (m, 1H), 7.11-7.08 (m, 2H), 3.27 (s, 1H), 2.77 (s, 2H), 1.39 (s, 6H) ppm; ${ }^{13} \mathrm{C}$ NMR $\left(\mathrm{CDCl}_{3}, 100 \mathrm{MHz}\right) \delta 171.6,150.3,129.7,126.3,121.7,69.4,46.6$, 29.4 ppm; IR (thin film) v 3438, 2975, 2934, 1750, 1493, 1457, 1480, 1192, 1162, 1105 $\mathrm{cm}^{-1}$. HRMS $\left(\mathrm{ES}^{+}\right)$calcd for $\mathrm{C}_{11} \mathrm{H}_{14} \mathrm{O}_{3} \mathrm{Na}^{+} 217.0841$ found 217.0837 [MNa $]$. 
$\overbrace{\mathrm{Me}}^{\mathrm{OH}}$

2-Methyl-5-(pyridin-2-yl)pentan-2-ol. (Table 4, Product 1)

Purified by chromatography on silica gel using 2.5\% $\mathrm{MeOH} / \mathrm{CH}_{2} \mathrm{Cl}_{2}$ (yellow oil, 59mg, 66\%). TLC $R_{f}=0.36\left(19: 1 \mathrm{CH}_{2} \mathrm{Cl}_{2} / \mathrm{MeOH}\right) ;{ }^{1} \mathrm{H}$ NMR $\left(\mathrm{CDCl}_{3}, 400 \mathrm{MHz}\right) \delta 8.58-8.43$ (m, 1H), 7.60 (td, 1H, $J=7.6,1.9 \mathrm{~Hz}), 7.19-7.05$ (m, 2H), 2.80 (t, 2H, $J=7.6 \mathrm{~Hz}), 1.89-$ $1.70(\mathrm{~m}, 2 \mathrm{H}), 1.61-1.43(\mathrm{~m}, 2 \mathrm{H}), 1.20(\mathrm{~s}, 6 \mathrm{H}) ;{ }^{13} \mathrm{C} \mathrm{NMR}\left(\mathrm{CDCl}_{3}, 100 \mathrm{MHz}\right) \delta 161.9$, 148.9, 136.8, 123.1, 121.3, 70.9, 43.2, 38.3, 29.4, 24.7 ppm; IR (thin film) v 3371, 2967, 2359, 1717, 1593, 1436, $1150 \mathrm{~cm}^{-1}$; HRMS (ES ${ }^{+}$) calcd for $\mathrm{C}_{11} \mathrm{H}_{18} \mathrm{NO}^{+} 180.1384$ found $180.1393\left[\mathrm{MH}^{+}\right]$.

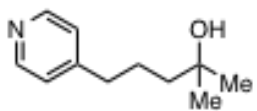

2-Methyl-5-(pyridin-4-yl)pentan-2-ol. (Table 4, Product 2)

Purified by chromatography on silica gel using 2.5\% $\mathrm{MeOH} / \mathrm{CH}_{2} \mathrm{Cl}_{2}$ (yellow oil, 45mg, $50 \%)$. TLC $R_{f}=0.36\left(19: 1 \mathrm{CH}_{2} \mathrm{Cl}_{2} / \mathrm{MeOH}\right) ;{ }^{1} \mathrm{H}$ NMR $\left(\mathrm{CDCl}_{3}, 400 \mathrm{MHz}\right) \delta$ 8.56-8.35 (m, 2H), 7.21-7.01 (m, 2H), 2.62 (t, 2H, $J=7.6$ Hz), 2.14 (br s, 1H), 1.79-1.64 (m, 2H), 1.55-1.43 (m, 2H), 1.21 (s, 6H) ppm; ${ }^{13} \mathrm{C} \mathrm{NMR}\left(\mathrm{CDCl}_{3}, 100 \mathrm{MHz}\right) \delta$ 151.6, 149.6, 124.0, 70.6, 43.3, 35.7, 29.4, 25.1 ppm; IR (thin film) v 3326, 2966, 2866, 1604, 1558, 1416, $1219 \mathrm{~cm}^{-1}$; HRMS $\left(\mathrm{ES}^{+}\right.$) calcd for $\mathrm{C}_{11} \mathrm{H}_{18} \mathrm{NO}^{+}$180.1384, found $180.1404\left[\mathrm{MH}^{+}\right]$.

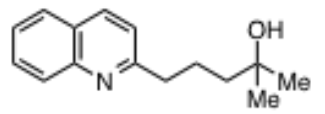

2-Methyl-5-(quinolin-2-yl)pentan-2-ol. (Table 4, Product 3)

Purified by chromatography on silica gel using 30\% acetone/hexanes (white solid, 49mg, 43\%). TLC $R_{f}=0.38\left(19: 1 \mathrm{CH}_{2} \mathrm{Cl}_{2} / \mathrm{MeOH}\right) ;{ }^{1} \mathrm{H} \mathrm{NMR}\left(\mathrm{CDCl}_{3}, 400 \mathrm{MHz}\right) \delta 8.06(\mathrm{t}, 2 \mathrm{H}, J$ = 9.6 Hz), 7.79-7.76 (m, 1H), 7.68 (ddd, 1H, $J=8.4,7.0,1.4 \mathrm{~Hz}), 7.50-7.48(\mathrm{~m}, 1 \mathrm{H})$, 7.30 (d, 1H, $J=8.4 \mathrm{~Hz}$ ), 3.01 (t, 2H, $J=7.6 \mathrm{~Hz}), 2.94-1.90(\mathrm{~m}, 2 \mathrm{H}), 1.61-1.57(\mathrm{~m}, 2 \mathrm{H})$, 
1.22 (s, 6H) ppm; ${ }^{13} \mathrm{C}$ NMR $\left(\mathrm{CDCl}_{3}, 100 \mathrm{MHz}\right) \delta$ 162.6, 147.8, 136.5, 129.6, 128.7, 127.6, 126.8, 125.9, 121.6, 71.0, 43.2, 39.1, 29.5, 24.4 ppm; IR (thin film) v 3381, 3058, 2965, 1711, 1618, 1600, 1563, 1504, $827 \mathrm{~cm}^{-1}$. HRMS $\left(\mathrm{ES}^{+}\right)$calcd for $\mathrm{C}_{15} \mathrm{H}_{20} \mathrm{NO}^{+}$ 230.1545 found $230.1539\left[\mathrm{MH}^{+}\right]$.

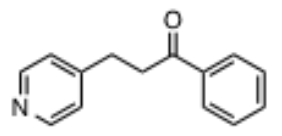

1-Phenyl-3-(pyridin-4-yl)propan-1-one. (Table 4, Product 4)

Purified by chromatography on silica gel using $20 \%$ acetone/hexanes (white solid, 63mg, $60 \%)$. TLC $R_{f}=0.62\left(19: 1 \mathrm{CH}_{2} \mathrm{Cl}_{2} / \mathrm{MeOH}\right) ;{ }^{1} \mathrm{H} \mathrm{NMR}\left(\mathrm{CDCl}_{3}, 400 \mathrm{MHz}\right) \delta 8.50(\mathrm{~d}, 2 \mathrm{H}$, $J=6.0 \mathrm{~Hz}$ ), 7.95 (d, 2H, $J=7.2 \mathrm{~Hz}$ ), 7.57 (t, 1H, $J=7.4 \mathrm{~Hz}$ ), 7.48-7.44 (m, 2H), 7.18 (d, $2 \mathrm{H}, J=6.0 \mathrm{~Hz}$ ), $3.33(\mathrm{t}, 2 \mathrm{H}, J=7.4 \mathrm{~Hz}), 3.07$ (t, $2 \mathrm{H}, J=7.4 \mathrm{~Hz}) \mathrm{ppm} ;{ }^{13} \mathrm{C} \mathrm{NMR}\left(\mathrm{CDCl}_{3}\right.$, $100 \mathrm{MHz}) \delta$ 198.7, 150.7, 150.3, 137.0, 133.8, 129.1, 128.4, 124.3, 39.3, 29.6; IR (thin film) $v$ 3583, 2956, 2359, 1712, 1683, 1579, 1448, 1414, $1219 \mathrm{~cm}^{-1}$. HRMS (ES ${ }^{+}$) calcd for $\mathrm{C}_{14} \mathrm{H}_{14} \mathrm{NO}^{+} 212.1075$ found $212.1070\left[\mathrm{MH}^{+}\right]$.<smiles>CC(C)(O)CCCOC(=O)c1ccncc1</smiles>

4-Hydroxy-4-methylpentyl isonicotinate. (Table 4, Product 5)

Purified by chromatography on silica gel using $50 \%$ acetone/hexanes (white solid, $45 \mathrm{mg}$, 40\%). TLC $R_{f}=0.35\left(19: 1 \mathrm{CH}_{2} \mathrm{Cl}_{2} / \mathrm{MeOH}\right) ;{ }^{1} \mathrm{H} \mathrm{NMR}\left(\mathrm{CDCl}_{3}, 400 \mathrm{MHz}\right) \delta 8.79(\mathrm{dd}, 2 \mathrm{H}$, $J=4.6,1.4 \mathrm{~Hz}$ ), 7.86 (dd, 2H, $J=4.5,1.5 \mathrm{~Hz}), 4.39$ (t, 2H, $J=4.6,6.7 \mathrm{~Hz}), 1.94-1.87$ (m, 2H), 1.9 (s, 1H), 1.64-1.60 (m, 2H), 1.28 (s, 6H) ppm; ${ }^{13} \mathrm{C} \mathrm{NMR}\left(\mathrm{CDCl}_{3}, 100 \mathrm{MHz}\right) \delta$ 165.2, 150.7, 137.6, 123.0, 70.6, 66.3, 39.9, 29.5, 23.8 ppm; IR (thin film) v 3386, 2966, $1728,1408,1324,1284,1124 \mathrm{~cm}^{-1}$. 
$\mathrm{PhS}(\mathrm{O})_{2} \mathrm{O}-\mathrm{Me}$

4-Acetylphenyl benzenesulfonate (Table 2, Product 2). ${ }^{21 \mathrm{c}}$

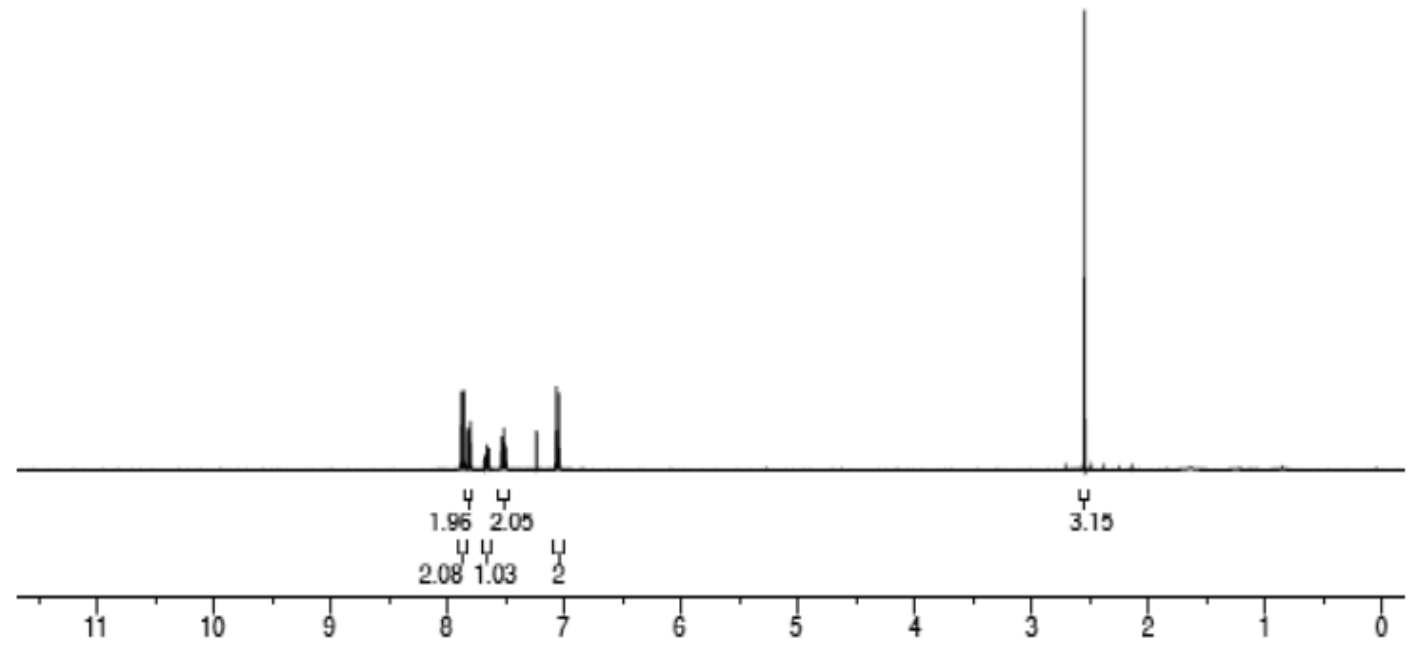

Me $\mathrm{NHSO}_{2} \mathrm{CF}_{3}$

1,1,1-Trifluoro- $N$-(3-hydroxy-3-methylbutyl)methanesulfonamide (Table 2, Product 3). ${ }^{21 c}$

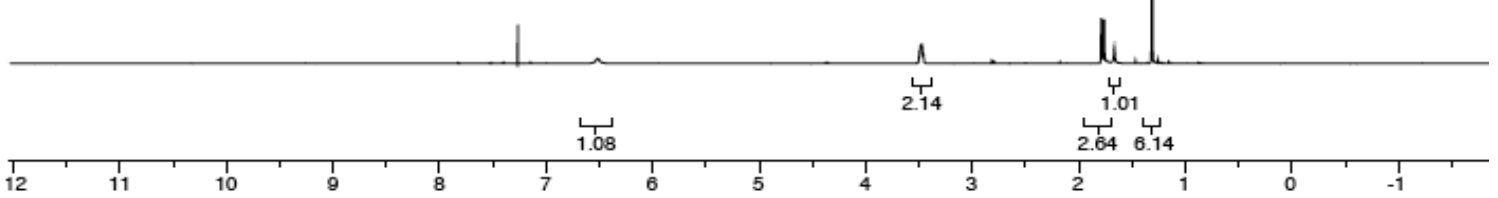


${ }_{\mathrm{H}_{3} \mathrm{CO}}^{\mathrm{HO}} \stackrel{\mathrm{CH}_{3}}{\mathrm{OSO}_{2} \mathrm{Me}}$

2-hydroxy-2-methylpropyl methanesulfonate. (Table 2, Product 5)
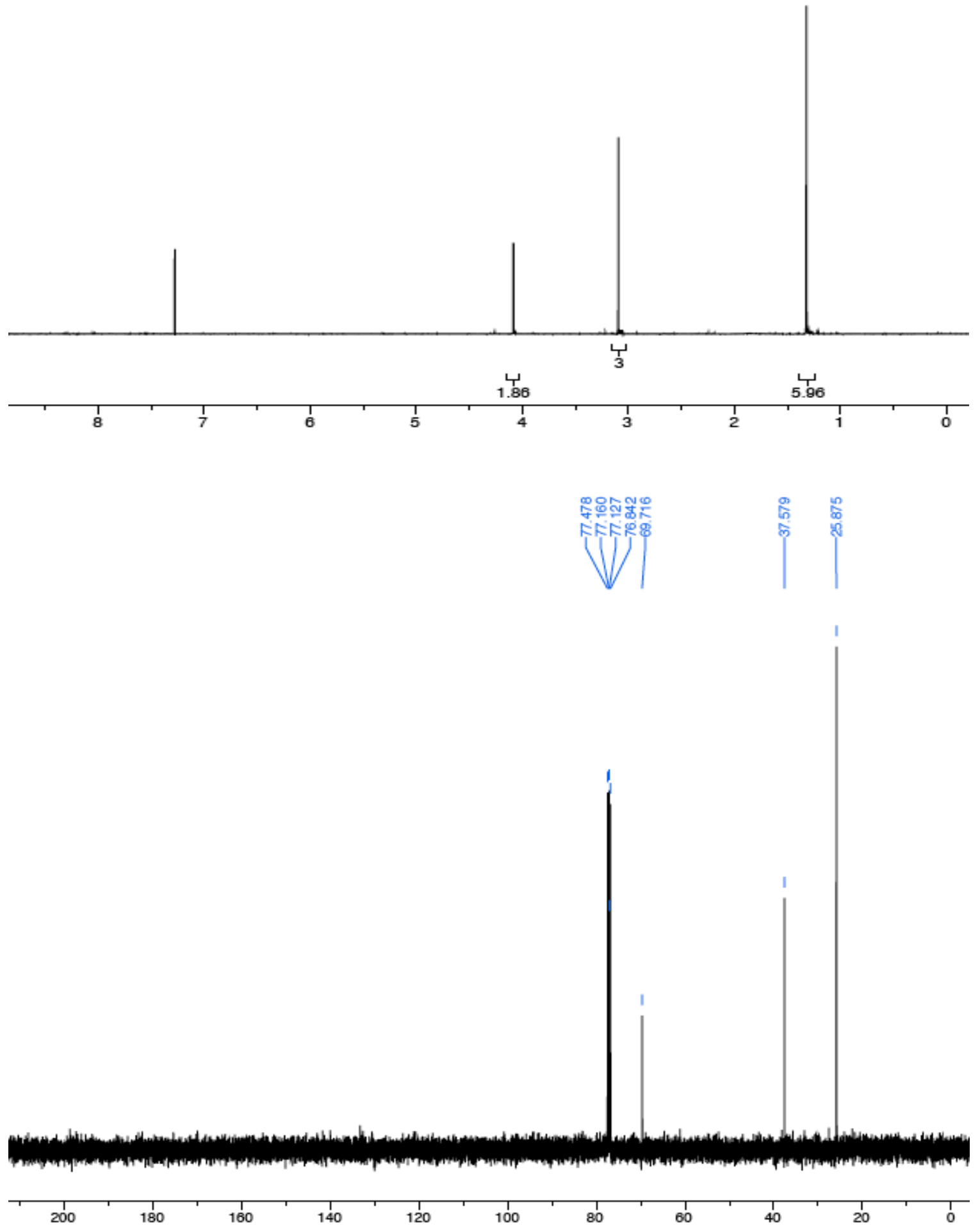


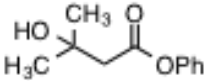

Phenyl 3-hydroxy-3-methylbutanoate. (Table S2, Product 6)

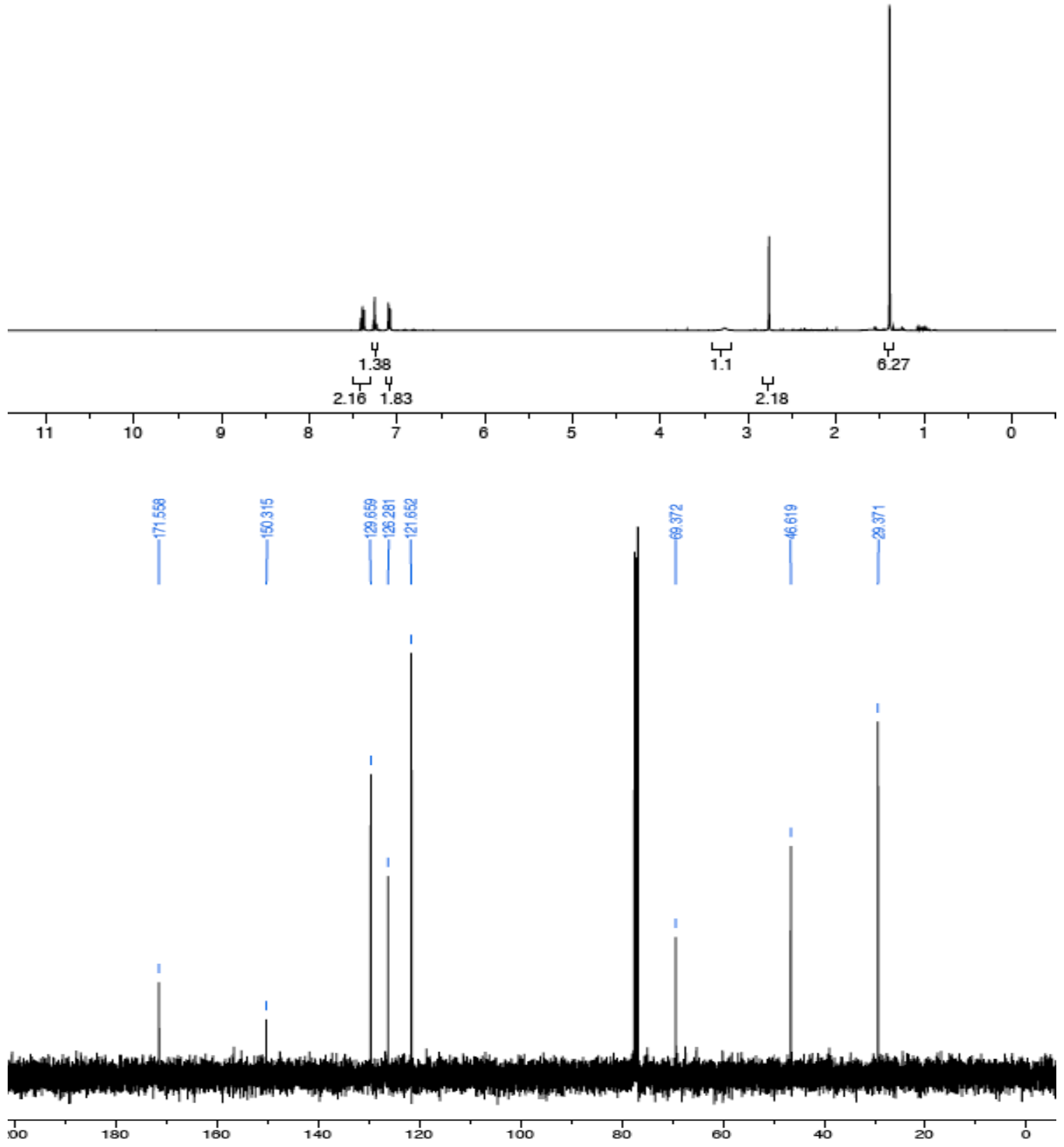




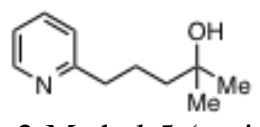

2-Methyl-5-(pyridin-2-yl)pentan-2-ol (Table 4, Product 1)
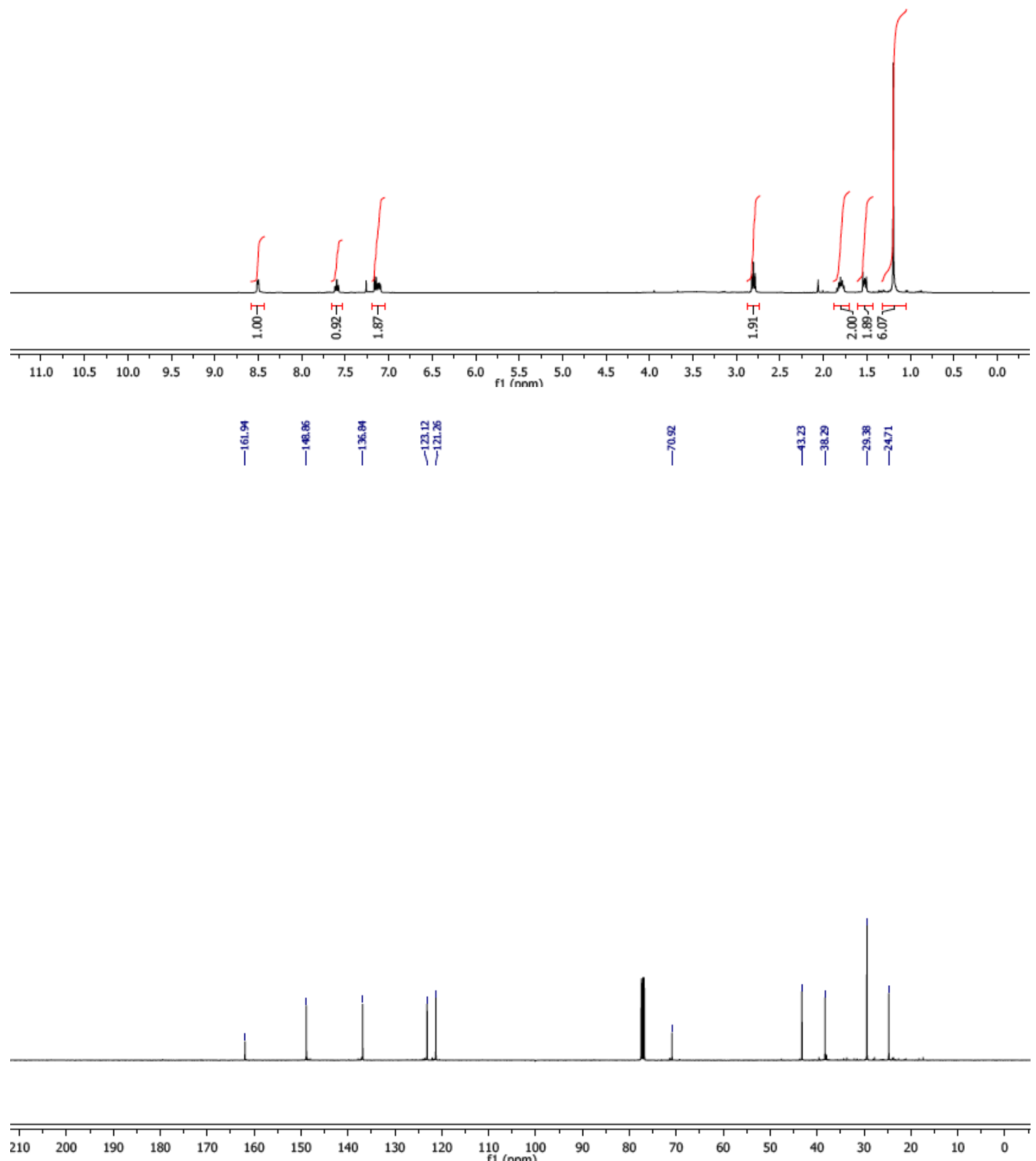


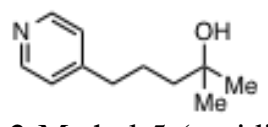

2-Methyl-5-(pyridin-4-yl)pentan-2-ol. (Table 4, Product 2)
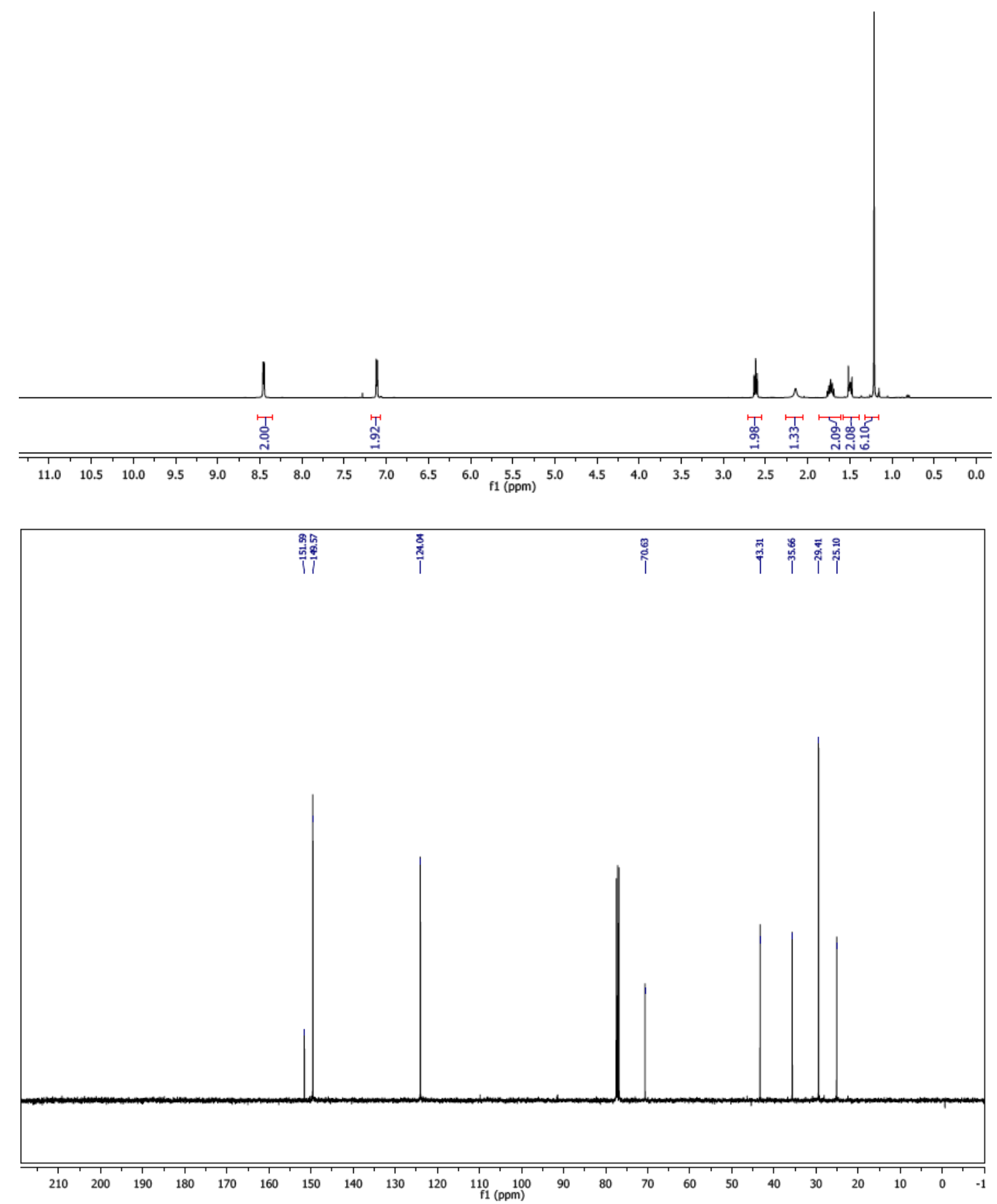


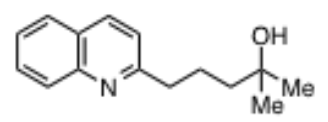

2-Methyl-5-(quinolin-2-yl)pentan-2-ol.(Table 4, Product 3)

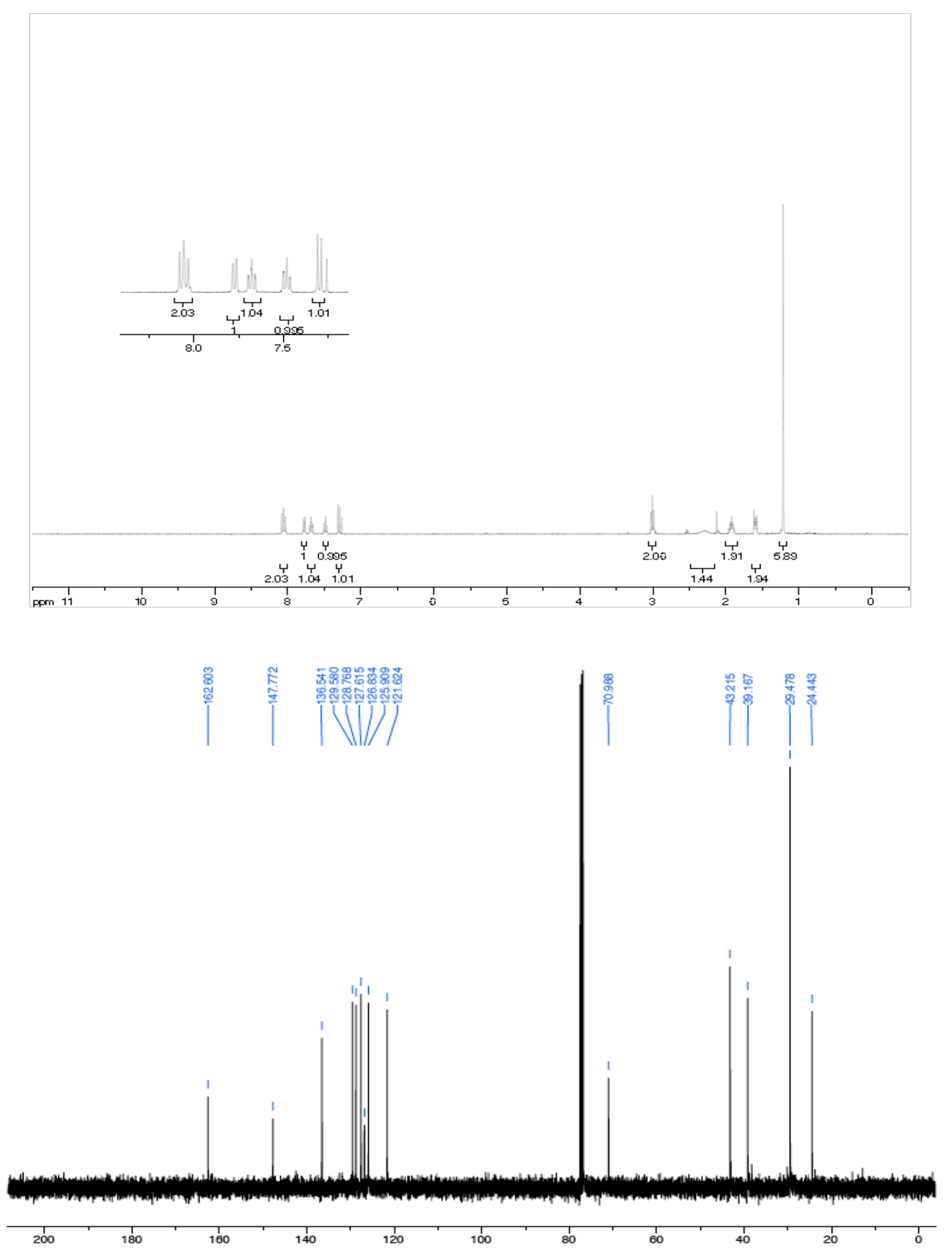




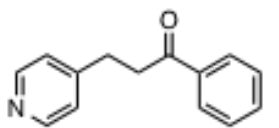

1-Phenyl-3-(pyridin-4-yl)propan-1-one. (Table 4, Product 4)
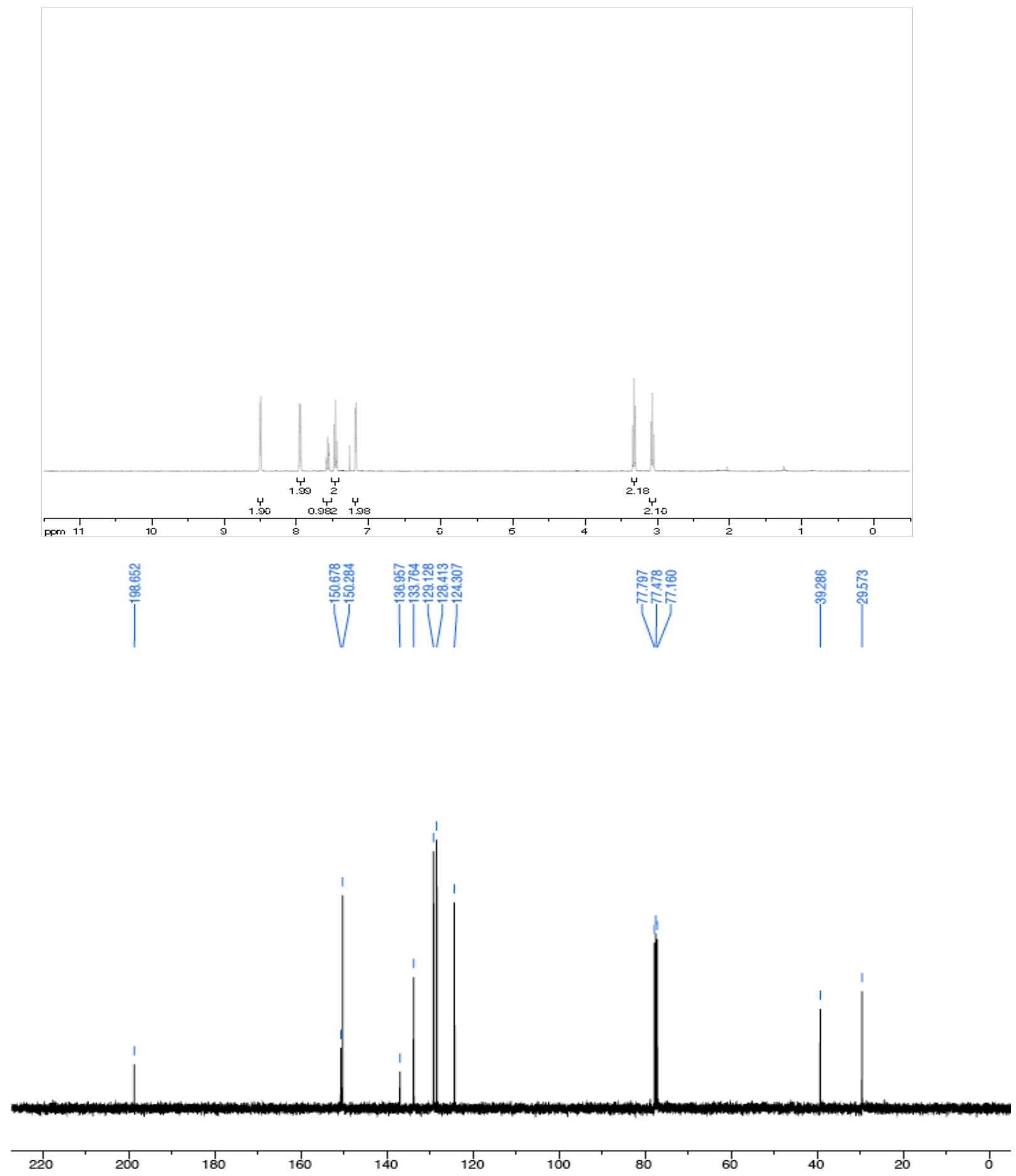


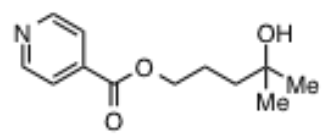

4-Hydroxy-4-methylpentyl isonicotinate. (Table 4, Product 5)
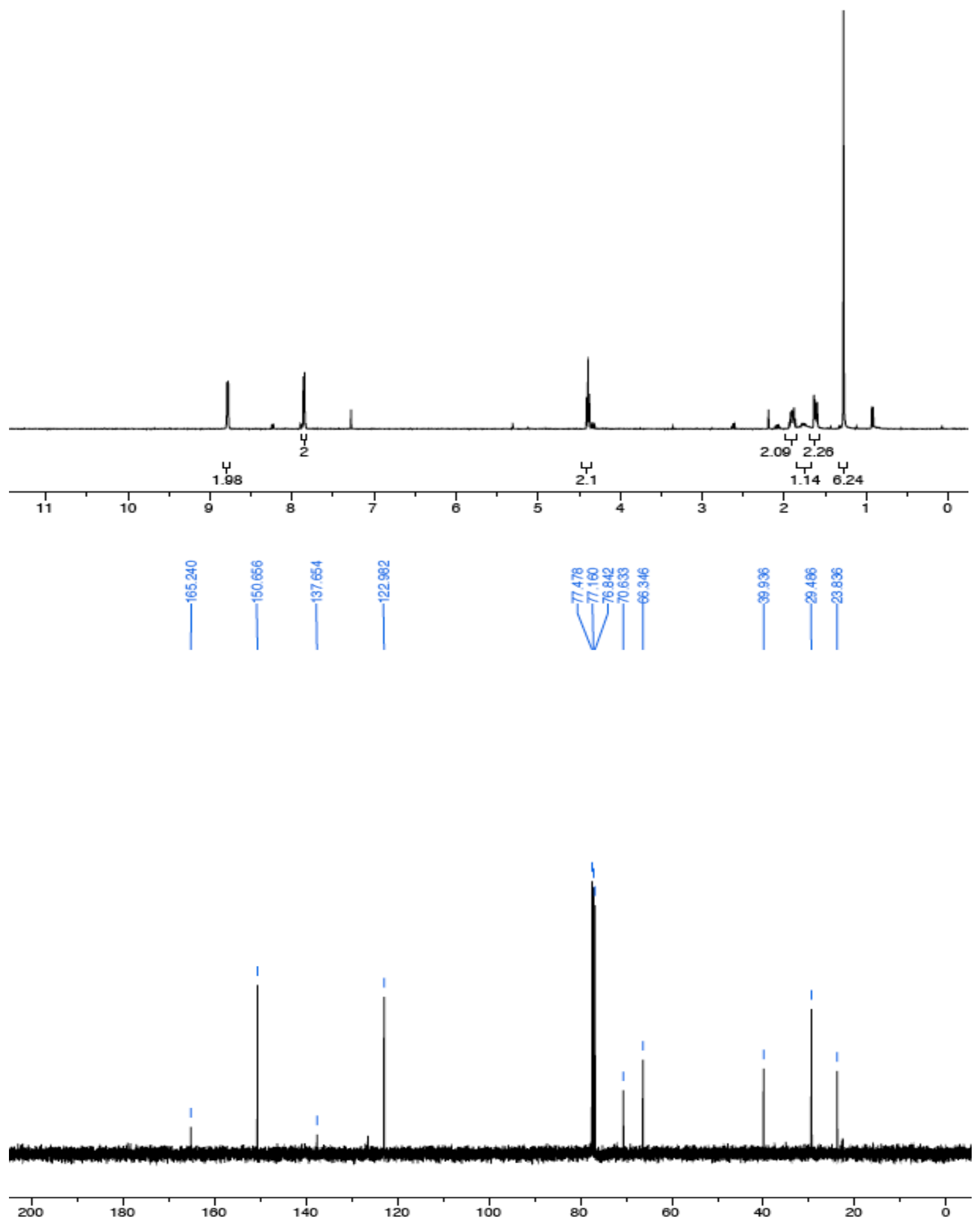


\section{General Experimental Details}

Unless otherwise noted, all reactions were conducted under ambient conditions with magnetic stirring. Acetic acid (Sigma Aldrich), $\mathrm{Mn}(\mathrm{OTf})_{2}$ (Sigma Aldrich), and 2,2'bipyridine (Alfa Aesar) were used as received and transfer under ambient atmosphere. Peracetic acid (Sigma Aldrich), Fe-(S,S-PDP) (Strem), and $\mathrm{AgClO}_{4}$ (Strem) were used as received and stored at $4{ }^{\circ} \mathrm{C}$. Mn-(S,S-PDP) was synthesized following known procedures and was stored under nitrogen at $4{ }^{\circ} \mathrm{C} .{ }^{1}$

Chromatographic purification of products was accomplished using forced flow chromatography on Kieselgel 60 (230-400 mesh) silica gel. Thin layer chromatography was performed on Kieselgel silica gel 60 F254 plates $(250 \mu \mathrm{m})$. Visualization of the developed chromatogram was accomplished by fluorescence quenching and by staining with ethanolic anisaldehyde, aqueous potassium permanganate, or aqueous ceric ammonium molybdate (CAM) solution.

${ }^{1} \mathrm{H}$ NMR spectra were measured at $400 \mathrm{MHz}$ on a Bruker Avance instrument and are referenced internally according to residual solvent signals $\left(\delta 7.26\right.$ for $\left.\mathrm{CHCl}_{3}\right)$. For quantitative NMR analyses, the delay time was set to 30 seconds $(\mathrm{d} 1=30)$ and the number of scans was set to $16(\mathrm{nt}=16) .{ }^{2}{ }^{13} \mathrm{C}$ NMR spectra were recorded at $100 \mathrm{MHz}$ in

${ }^{1} \mathrm{H}$ and heteroatom-decoupled mode. The signal from residual chloroform $(\delta 77.0)$ was used as an internal reference. Infrared (IR) spectra were recorded as thin films using $\mathrm{NaCl}$ plates on a Thermo-Nicolet $300 \mathrm{FT}$-IR spectrometer and are reported in frequency of absorption. High resolution mass spectra were obtained from the Vincent Coates Foundation Mass Spectrometry Laboratory at Stanford University.

1. Ottenbacher, R. V.; Samsonenko, D. G.; Talsi, E. P.; Bryliakov, K. P. Highly efficient, regioselective, and stereospecific oxidation of aliphatic $\mathrm{C}-\mathrm{H}$ groups with $\mathrm{H}_{2} \mathrm{O}_{2}$, catalyzed by aminopyridine manganese complexes. Org. Lett. 2012, 14, 4310-4313.

2. Maniara, G.; Rajamoorthi, K.; Rajan, S.; Stockton, G. Method Performance and Validation for Quantitative Analysis by ${ }^{1} \mathrm{H}$ and ${ }^{31} \mathrm{P}$ NMR Spectroscopy. Applications to Analytical Standards and Agricultural Chemicals. Anal. Chem., 1998, 70, 4921-4928. 

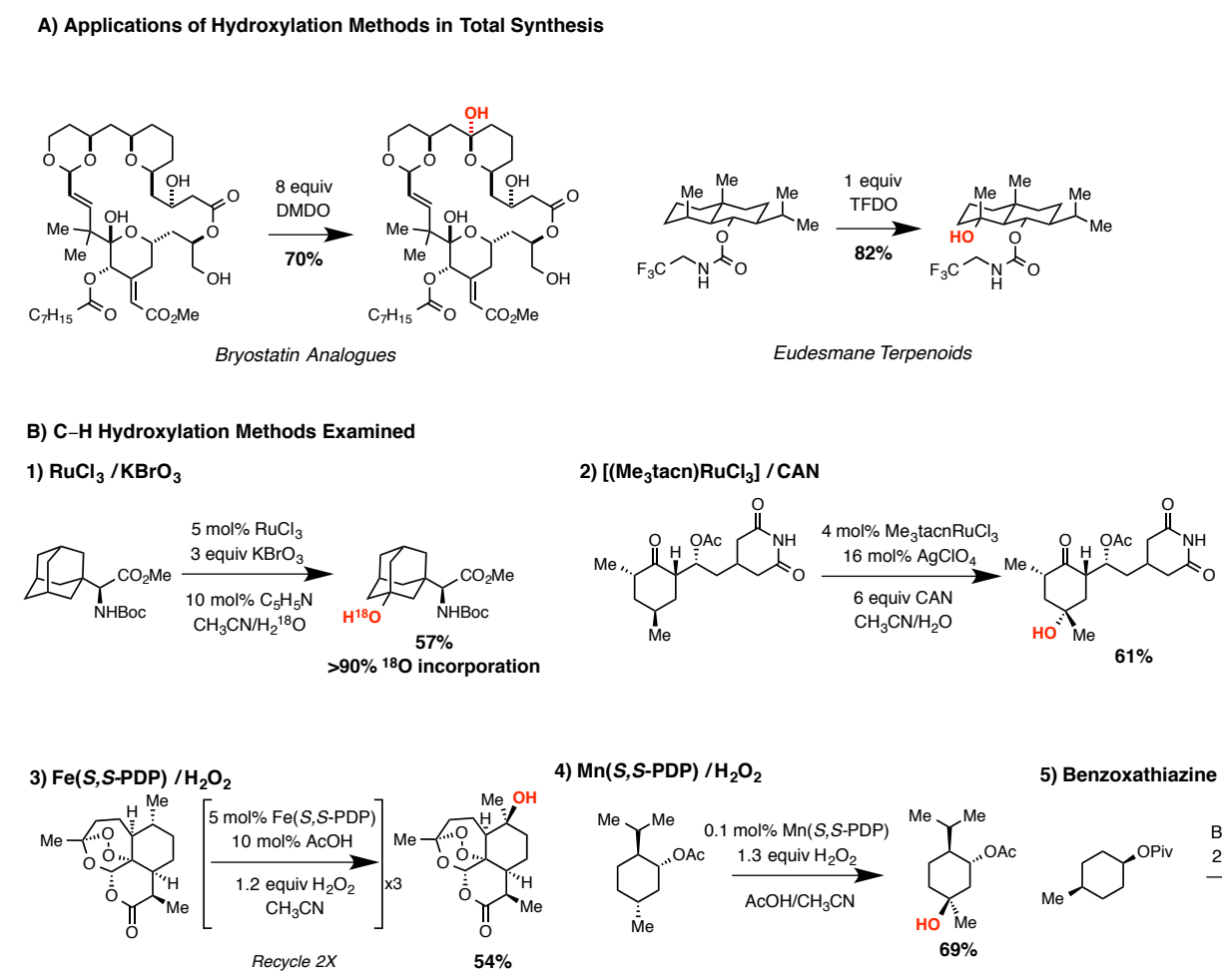

4) $\mathrm{Mn}(\mathrm{S}, \mathrm{S}-\mathrm{PDP}) / \mathrm{H}_{2} \mathrm{O}_{2}$
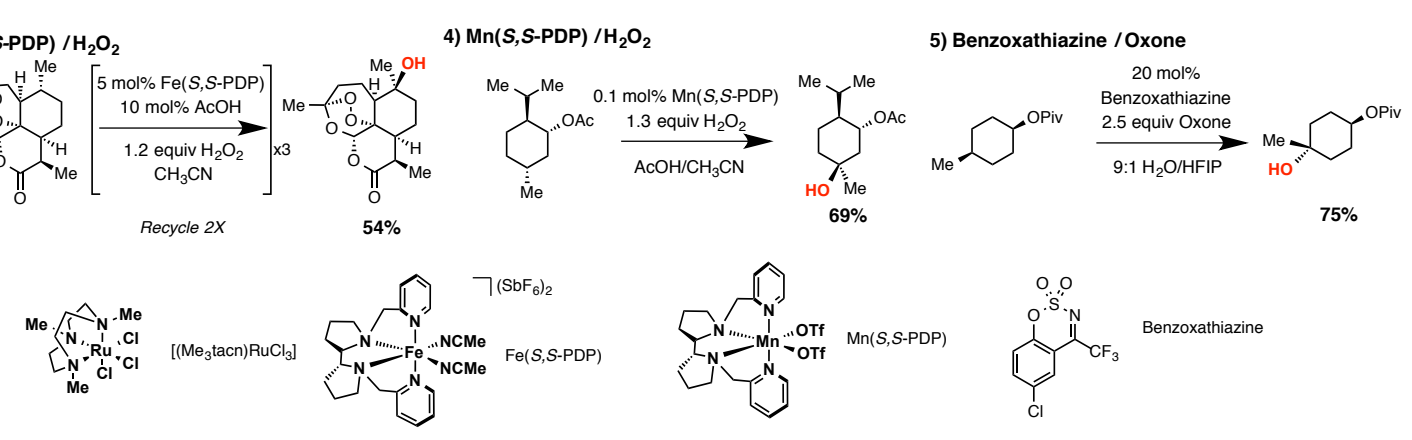

\section{Development of a Manganese System for $\mathbf{C}-\mathrm{H}$ hydroxylation}

\section{Screening Protocol}

Stock solutions were synthesized as follows: A $12.5 \mathrm{mM}$ solution of $\mathrm{Mn}(\mathrm{OTf})_{2}$ was prepared by dissolving $4.4 \mathrm{mg}$ of $\mathrm{Mn}(\mathrm{OTf})_{2}$ in $1.0 \mathrm{~mL}$ of a $9: 1 \mathrm{AcOH} / \mathrm{H}_{2} \mathrm{O}$ mixture. A $0.025 \mathrm{M}$ solution of ligand was prepared by dissolving ligand in $1.0 \mathrm{~mL}$ of $\mathrm{AcOH}$.

Modified commercial peracetic acid $\left(\mathrm{PAA}_{\mathrm{CM}}\right)$ was prepared by addition $10 \% \mathrm{KOH}(0.3$ $\mathrm{mL})$ to $35 \%$ peracetic acid in $\mathrm{AcOH}(1.0 \mathrm{~mL})$.

To a 20 dram vial containing 4-methylpentyl-2,4-difluorobenzoate (24 mg, $0.10 \mathrm{mmol}$ ), $\mathrm{AcOH}(0.48 \mathrm{~mL})$, and $\mathrm{H}_{2} \mathrm{O}(20 \mu \mathrm{L})$ was added sequentially solutions of $\mathrm{Mn}(\mathrm{OTf})_{2}(8 \mu \mathrm{L}$, 0.001 equiv) and ligand ( $40 \mu \mathrm{L}, 0.01$ equiv). The clear solution was stirred for $10 \mathrm{~min}$ 
before a solution of $\mathrm{PAA}_{\mathrm{CM}}(88 \mu \mathrm{L}, 0.3 \mathrm{mmol})$ was added dropwise. Note: the addition of $\mathrm{PAA}_{\mathrm{CM}}$ results in a significant exotherm; caution should be taken. After $90 \mathrm{~s}$, the reaction was diluted with $10 \mathrm{~mL}$ of acetone, stirred for 30 seconds and filtered through a small pad of Celite. The flask and filter cake were rinsed with $\sim 20 \mathrm{~mL}$ of acetone, and the combined filtrates were concentrated under reduced pressure.

Table S.1. Optimization of metal-to-ligand ratio using substrate 1 .

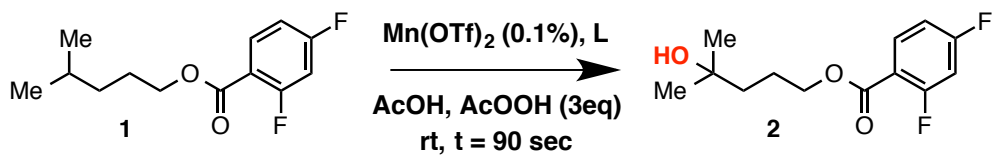

\begin{tabular}{cccc}
\hline Entry & Ligand & Ligand Loading & $\mathbf{1}_{\text {(Conversion) }}$ (Co $^{2}$ \\
\hline $\mathbf{1}$ & Phenanthroline & $0.20 \%$ & $24(44)$ \\
$\mathbf{2}$ & Phenanthroline & $0.50 \%$ & $35(60)$ \\
$\mathbf{3}$ & Phenanthroline & $1.00 \%$ & $46(85)$ \\
$\mathbf{4}$ & Bipyridine & $0.20 \%$ & $21(35)$ \\
$\mathbf{5}$ & Bipyridine & $0.50 \%$ & $32(52)$ \\
$\mathbf{6}$ & Bipyridine & $1.00 \%$ & $43(80)$ \\
$\mathbf{7}$ & Picolinic Acid & $0.10 \%$ & $8(12)$ \\
$\mathbf{8}$ & Picolinic Acid & $0.50 \%$ & $22(38)$ \\
$\mathbf{9}$ & Picolinic Acid & $1.00 \%$ & $37(72)$ \\
$\mathbf{1 0}$ & Terpyridine & $1.00 \%$ & $37(62)$ \\
$\mathbf{1 1}$ & Terpyridine & $5.00 \%$ & $30(50)$ \\
$\mathbf{1 2}$ & None & $0.00 \%$ & $0(0)$ \\
\hline
\end{tabular}

a) Differences between formation of product 2 and percent conversion derive from methylene oxidation on the alkyl chain. Percent conversions were measured by ${ }^{19} \mathrm{~F}$ and ${ }^{1} \mathrm{H}$ NMR integrations.

\section{Reaction Protocol}

To a 20 dram vial containing substrate $(1.0 \mathrm{mmol})$, $\mathrm{AcOH}(4.8 \mathrm{~mL})$, and $\mathrm{H}_{2} \mathrm{O}(0.2 \mathrm{~mL})$ was added solid $\mathrm{Mn}(\mathrm{OTf})_{2}(0.3 \mathrm{mg}, 1.0 \mu \mathrm{mol}, 0.001$ equiv), and bipyridine (1.6 mg, 1.0 $\mu \mathrm{mol}, 0.01$ equiv). After stirring for $10 \mathrm{~min}, \mathrm{PAA}_{\mathrm{CM}}$ solution $(0.88 \mathrm{~mL}, 3.6 \mathrm{M}, 3.0$ equiv) was added dropwise over $90 \mathrm{~s}$. After an additional $90 \mathrm{~s}$ of stirring, the reaction mixture was diluted with $10 \mathrm{~mL}$ of EtOAc and transferred to a separatory funnel containing $20 \mathrm{~mL}$ of saturated aqueous $\mathrm{Na}_{2} \mathrm{~S}_{2} \mathrm{O}_{3}$. The organic layer was collected and the 
aqueous layer was extracted with $2 \times 20 \mathrm{~mL}$ with EtOAc. The combined organic extracts were washed with $15 \mathrm{~mL}$ of $\mathrm{H}_{2} \mathrm{O}$ and $15 \mathrm{~mL}$ of saturated aqueous $\mathrm{NaCl}$, dried over $\mathrm{Na}_{2} \mathrm{SO}_{4}$, filtered, and concentrated under reduced pressure. Purification of this material by chromatography on silica gel (conditions given below) afforded the desired product.

Table S.1. Substrate scope of the manganese catalyzed C-H oxidation reaction.

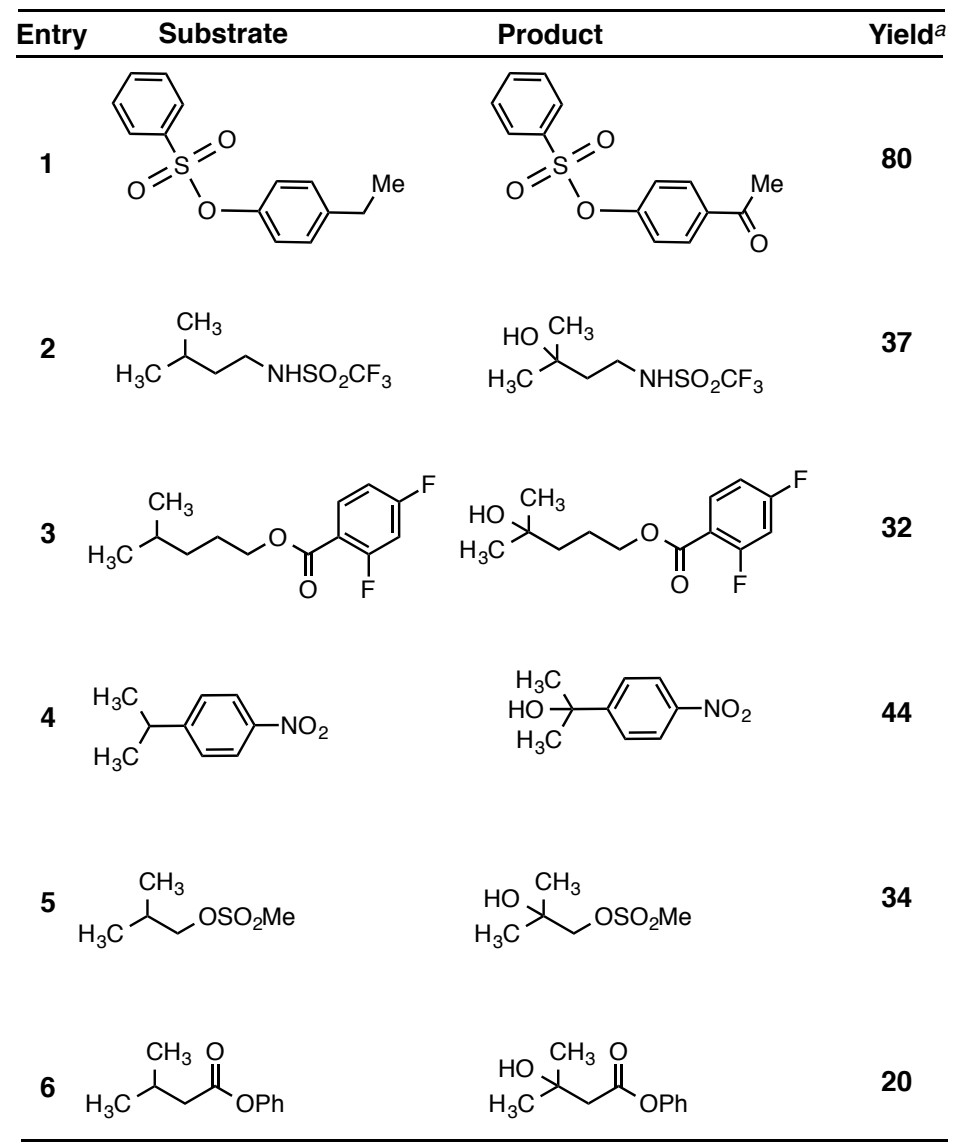

a) Reaction conducted on a $1 \mathrm{mmol}$ scale with $\mathrm{Mn}(\mathrm{OTf})_{2}(0.1 \%)$, bipyridine (1\%), $\mathrm{AcOOH}(3.0$ eq), $\mathrm{AcOH}, 90$ seconds.

\section{Comparative Reaction Screening}

\section{Screening Reaction Protocols}

All reactions were conducted on a $0.25 \mathrm{mmol}$ scale. After drying all reactions to remove any residual solvent, pyrazine $(10 \mathrm{mg}, 0.125 \mathrm{mmol})$ was added to each reaction. The mixture was dissolved in deuterated solvent and analyzed by ${ }^{1} \mathrm{H}$ NMR. 


\section{$\mathrm{RuCl}_{3}$-catalyzed oxidation}

A 20 dram vial was charged with $\mathrm{RuCl}_{3} \cdot \mathrm{H}_{2} \mathrm{O}\left(2.6 \mathrm{mg}, 12.5 \mu \mathrm{mol}, 0.05\right.$ equiv) and $\mathrm{KBrO}_{3}$ (125 mg, $0.75 \mathrm{mmol}, 3.0$ equiv). To this mixture was added $2.0 \mathrm{~mL}$ of $\mathrm{H}_{2} \mathrm{O}$ and pyridine $(2.0 \mu \mathrm{L}, 25.0 \mu \mathrm{mol}, 0.10$ equiv), followed by a solution of substrate $(0.25 \mathrm{mmol})$ in 2.0 $\mathrm{mL}$ of $\mathrm{CH}_{3} \mathrm{CN}$. The pale yellow solution was stirred at $60{ }^{\circ} \mathrm{C}$ for $24 \mathrm{~h}$. Following this time, the reaction mixture was quenched with $2 \mathrm{~mL}$ of saturated aqueous $\mathrm{Na}_{2} \mathrm{~S}_{2} \mathrm{O}_{3}$ and the contents transferred to a separatory funnel with $30 \mathrm{~mL}$ of $\mathrm{H}_{2} \mathrm{O}$. The aqueous mixture was extracted with $3 \times 25 \mathrm{~mL}$ of EtOAc. The combined organic fractions were washed $1 \times 25$ $\mathrm{mL}$ of saturated aqueous $\mathrm{NaCl}$, dried over $\mathrm{MgSO}_{4}$, filtered, and concentrated under reduced pressure.

\section{[( $\left.\left.\mathrm{Me}_{3} \mathrm{tacn}\right) \mathrm{RuCl}_{3}\right]$-catalyzed oxidation}

A 20 dram vial was charged with $\left[\left(\mathrm{Me}_{3} \mathrm{tacn}\right) \mathrm{RuCl}_{3}\right](2 \mathrm{mg}, 5.0 \mu \mathrm{mol}, 0.02$ equiv), $\mathrm{AgClO}_{4}$ (4 mg, $0.02 \mathrm{mmol}, 0.08$ equiv), and $2.0 \mathrm{~mL}$ of $\mathrm{H}_{2} \mathrm{O}$. The mixture was stirred at $80{ }^{\circ} \mathrm{C}$ for 5 min during which time $\mathrm{AgCl}$ precipitation was observed. After cooling the solution to ambient temperature, a solution of substrate $(0.25 \mathrm{mmol})$ in $2.0 \mathrm{~mL}$ of tertbutanol was added, followed by ceric ammonium nitrate (411 mg, $0.75 \mathrm{mmol}, 3.0$ equiv). This mixture was stirred for $15 \mathrm{~min}$ following which time an additional $411 \mathrm{mg}$ of ceric ammonium nitrate was added. The reaction was stirred for and additional $4 \mathrm{~h}$ prior to being quenched with $1 \mathrm{~mL}$ of $\mathrm{MeOH}$. The resulting yellow solution was transferred to a separatory funnel containing $30 \mathrm{~mL}$ of $\mathrm{H}_{2} \mathrm{O}$. The aqueous mixture was extracted with $2 \mathrm{x}$ $25 \mathrm{~mL}$ of EtOAc. The combined organic fractions were washed with $25 \mathrm{~mL}$ of $\mathrm{H}_{2} \mathrm{O}$ and $25 \mathrm{~mL}$ of saturated aqueous $\mathrm{NaCl}$, dried over $\mathrm{MgSO}_{4}$, filtered and concentrated under reduced pressure.

\section{$\operatorname{Mn}(\mathrm{OTf})_{2} /$ bipyridine-catalyzed oxidation}

A $12.5 \mathrm{mM}$ solution of $\mathrm{Mn}(\mathrm{OTf})_{2}$ was prepared by dissolving $4.4 \mathrm{mg}$ of $\mathrm{Mn}(\mathrm{OTf})_{2}$ in 1.0 $\mathrm{mL}$ of a 9:1 AcOH/ $\mathrm{H}_{2} \mathrm{O}$ solution. A $0.025 \mathrm{M}$ solution of 2,2'-bipyridine was prepared by dissolving $3.9 \mathrm{mg}$ of bipyridine in $1.0 \mathrm{~mL}$ of $\mathrm{AcOH}$.

Modified commercial peracetic acid was prepared by mixing $1.0 \mathrm{~mL}$ of commercial peracetic acid solution (35\% Aldrich) with $0.3 \mathrm{~mL}$ of $10 \% \mathrm{KOH}$ solution. 
To a 20 dram reaction vial with containing substrate $(0.25 \mathrm{mmol})$ was added $1.25 \mathrm{~mL}$ of $\mathrm{AcOH}$, followed by solutions of $\mathrm{Mn}(\mathrm{OTf})_{2}(20 \mu \mathrm{L}, 0.25 \mu \mathrm{mol}, 0.001$ equiv) and bipyridine (100 $\mu \mathrm{L}, 2.5 \mu \mathrm{mol}, 0.01$ equiv). The colorless mixture was stirred for $10 \mathrm{~min}$ prior to the dropwise addition $(30 \mathrm{~s})$ of a solution of PAA $\mathrm{CM}_{\mathrm{CM}}(220 \mu \mathrm{L}, 0.75 \mathrm{mmol}, 3.0$ equiv). Note: the addition of $\mathrm{PAA}_{\mathrm{CM}}$ results in a significant exotherm; caution should be taken. After $60 \mathrm{~s}$, the reaction was diluted with $5 \mathrm{~mL}$ of acetone and stirred for 30 seconds and filtered through a small pad of Celite. The flask and filter cake were rinsed with $\sim 25 \mathrm{~mL}$ of acetone, and the combined filtrates were concentrated under reduced pressure.

\section{$M n-(\mathrm{S}, \mathrm{S}-P D P)$-catalyzed oxidation}

A $5.0 \mathrm{mM}$ solution of $\mathrm{Mn}-(S, S-\mathrm{PDP})$ was prepared by dissolving $3.4 \mathrm{mg}$ of catalyst in 1.0 $\mathrm{mL}$ of $\mathrm{CH}_{3} \mathrm{CN}$.

A $7 \mathrm{~mL}$ vial was charged with substrate $(0.25 \mathrm{mmol}), 950 \mu \mathrm{L}$ of $\mathrm{CH}_{3} \mathrm{CN}$, and $\mathrm{AcOH}(200$ $\mu \mathrm{L}, 3.5 \mathrm{mmol}, 14.0$ equiv). To this mixture was added Mn-(S,S-PDP) catalyst solution (50 $\mu \mathrm{L}, 0.25 \mu \mathrm{mol}, 0.001$ equiv). The colorless solution was cooled to $0{ }^{\circ} \mathrm{C}$ and an solution of $\mathrm{H}_{2} \mathrm{O}_{2}$ (35 wt\%, $28 \mu \mathrm{L}, 0.325 \mathrm{mmol}, 1.3$ equiv) in $250 \mu \mathrm{L}$ of $\mathrm{CH}_{3} \mathrm{CN}$ was added dropwise over $1 \mathrm{~h}$. Upon addition of $\mathrm{H}_{2} \mathrm{O}_{2}$, the solution changes to a pale yellow color that persists for the entirety of the reaction. The reaction was stirred at $0{ }^{\circ} \mathrm{C}$ for an additional $1 \mathrm{~h}$. Following this time, the reaction was quenched with $3 \mathrm{~mL}$ of aqueous $\mathrm{NaHCO}_{3}$. The solution was transferred to a separatory funnel with $10 \mathrm{~mL}$ of EtOAc. The organic phase was collected and the aqueous layer was extracted with $2 \times 20 \mathrm{~mL}$ of EtOAc. The combined organic fractions were washed with $25 \mathrm{~mL}$ of $\mathrm{H}_{2} \mathrm{O}$ and $25 \mathrm{~mL}$ of saturated aqueous $\mathrm{NaCl}$, dried over $\mathrm{MgSO}_{4}$, filtered and concentrated under reduced pressure.

\section{Fe-(S,S-PDP)-catalyzed oxidation}

In two separate vials, solutions containing Fe-(S,S-PDP) (12 mg, $12.5 \mu \mathrm{mol}, 0.05$ equiv), $\mathrm{AcOH}$ ( $7.5 \mathrm{mg}, 0.125 \mathrm{mmol}, 0.5$ equiv) in $250 \mu \mathrm{L}$ of $\mathrm{CH}_{3} \mathrm{CN}$ were prepared.

A 20 dram vial was charged with Fe-(S,S-PDP) (12 mg, $12.5 \mu$ mol, 0.05 equiv), substrate $(0.25 \mathrm{mmol}), \mathrm{AcOH}\left(7.5 \mathrm{mg}, 0.125 \mathrm{mmol}, 0.5\right.$ equiv), and $375 \mu \mathrm{L}$ of $\mathrm{CH}_{3} \mathrm{CN}$. 
To this dark purple mixture was added dropwise ( $45 \mathrm{~s}$ ) a solution of $\mathrm{H}_{2} \mathrm{O}_{2}(50 \mathrm{wt} \%, 18.4$ $\mu \mathrm{L}, 0.3 \mathrm{mmol}, 1.2$ equiv) in $2.25 \mathrm{~mL}$. After stirring for $10 \mathrm{~min}$, an aliquot $(250 \mu \mathrm{L})$ of the Fe-(S,S-PDP) solution was added dropwise. This was followed by the dropwise addition ( $45 \mathrm{~s}$ ) of a solution of $\mathrm{H}_{2} \mathrm{O}_{2}(50 \mathrm{wt} \%, 18.4 \mu \mathrm{L}, 0.3 \mathrm{mmol}, 1.2$ equiv) in $2.25 \mathrm{~mL}$ of $\mathrm{CH}_{3} \mathrm{CN}$. Following another 10 min period, this process was repeated with the second aliquot of the Fe-(S,S-PDP) mixture. After stirring for an additional $10 \mathrm{~min}$, the dark amber solution was concentrated under reduced pressure to a volume of $\sim 1 \mathrm{~mL}$, diluted with $20 \mathrm{~mL}$ of $\mathrm{Et}_{2} \mathrm{O}$, and filtered through a small pad of Celite. The flask and filter cake were rinsed with $\sim 20 \mathrm{~mL}$ of $\mathrm{Et}_{2} \mathrm{O}$ and the filtrate concentrated under reduced pressure to an oily residue. To remove residual $\mathrm{AcOH}$, the unpurified product was dissolved in 20 $\mathrm{mL}$ of $\mathrm{Et}_{2} \mathrm{O}$ and filtered through a Supelco bicarbonate column. The flask and filter were rinsed with $\sim 50 \mathrm{~mL}$ of $\mathrm{Et}_{2} \mathrm{O}$ and the filtrate and concentrated under reduced pressure.

\section{Benzoxathiazine-catalyzed oxidation}

To a $7 \mathrm{~mL}$ screwtop vial was added substrate $(0.25 \mathrm{mmol})$, benzoxathiazine catalyst (14 $\mathrm{mg}, 0.05 \mathrm{mmol}, 0.2$ equiv), Oxone (192 mg, 2.5 equiv, $0.625 \mathrm{mmol}), 100 \mu \mathrm{L}$ of HFIP and $900 \mu \mathrm{L}$ of $\mathrm{H}_{2} \mathrm{O}$. The vial was sealed and the reaction mixture was stirred at $70{ }^{\circ} \mathrm{C}$ for 12 or $24 \mathrm{~h}$. Following this time, the solution was cooled to ambient temperature and transferred to a separatory funnel with $15 \mathrm{~mL}$ of EtOAc and $25 \mathrm{~mL}$ of $\mathrm{H}_{2} \mathrm{O}$. The organic layer was collected and the aqueous phased was extracted with $2 \mathrm{x}$ by $25 \mathrm{~mL}$ of EtOAc. The combined organic extracts were dried over $\mathrm{MgSO}_{4}$, filtered, and concentrated under reduced pressure.

\subsubsection{Protocols for oxidation of pyridyl substrates.}

$\left[\left(\mathrm{Me}_{3} \mathrm{tacn}\right) \mathrm{RuCl}_{3}\right]:$ A 20 dram vial was charged with $\left[\left(\mathrm{Me}_{3} \mathrm{tacn}\right) \mathrm{RuCl}_{3}\right]$ (4 mg, 10.0 $\mu$ mol, 0.02 equiv), $\mathrm{AgClO}_{4}\left(8 \mathrm{mg}, 40 \mu \mathrm{mol}, 0.08\right.$ equiv), and $4.0 \mathrm{~mL}$ of $\mathrm{H}_{2} \mathrm{O}$. The mixture was stirred at $80{ }^{\circ} \mathrm{C}$ for 5 min during which time $\mathrm{AgCl}$ precipitation was observed. After cooling the reaction to room temperature, a solution of substrate ( 0.5 $\mathrm{mmol}$ ) in $4.0 \mathrm{~mL}$ of $t-\mathrm{BuOH}$ was added, followed by portionwise addition of solid ceric ammonium nitrate ( $822 \mathrm{mg}, 1.5 \mathrm{mmol}, 3.0$ equiv). This orange mixture was stirred for 15 min following which time an additional $822 \mathrm{mg}$ of ceric ammonium nitrate was added. 
The dark brown reaction mixture was stirred for $4 \mathrm{~h}$ then quenched with the addition of 1 $\mathrm{mL}$ of $\mathrm{MeOH}$. The solution was transferred to a separatory funnel containing $10 \mathrm{~mL}$ of 2 $\mathrm{N} \mathrm{NaOH}$ and $30 \mathrm{~mL}$ of EtOAc. The organic phase was collected and the aqueous layer was extracted with $3 \times 25 \mathrm{~mL}$ of EtOAc. The combined organic extracts were washed with $20 \mathrm{~mL}$ of saturated aqueous $\mathrm{NaCl}$, dried over $\mathrm{Na}_{2} \mathrm{SO}_{4}$, filtered and concentrated under reduced pressure. Purification of this material by chromatography on silica gel (conditions given below) afforded the desired product.

$\mathrm{Mn}(\mathrm{OTf})_{2}$-bipy: To a 20 dram reaction vial containing substrate $(0.5 \mathrm{mmol})$ was added $2.4 \mathrm{~mL}$ of $\mathrm{AcOH}, 100 \mu \mathrm{L}$ of $\mathrm{H}_{2} \mathrm{O}, \mathrm{Mn}(\mathrm{OTf})_{2}(0.2 \mathrm{mg}, 0.5 \mu \mathrm{mol}, 0.001$ equiv), and bipyridine $(0.8 \mathrm{mg}, 0.5 \mu \mathrm{mol}, 0.01$ equiv). The reaction mixture was stirred for $10 \mathrm{~min}$ prior to the dropwise addition $(30 \mathrm{~s})$ of a solution of $\mathrm{PAA}_{\mathrm{CM}}(440 \mu \mathrm{L}, 1.5 \mathrm{mmol}, 3.0$ equiv). The yellow solution was stirred for an additional $250 \mathrm{~s}$ and then diluted with 10 $\mathrm{mL}$ of acetone. The mixture was filtered through a Supelco bicarbonate column using an additional $30 \mathrm{~mL}$ of acetone to rinse the flask and filter. The filtrate was concentrated under reduced pressure to an oily residue. Purification of this material by chromatography on silica gel (conditions given below) afforded the desired product. 
Characterization of selected compounds.

$\mathrm{PhS}(\mathrm{O})_{2} \mathrm{O}-\longrightarrow \mathrm{O}_{\mathrm{O}}^{\mathrm{Me}}$

4-Acetylphenyl benzenesulfonate (Table 2, Product 2). ${ }^{21 \mathrm{c}}$

Purified by chromatography on silica gel using $15 \%$ acetone/hexanes (yellow oil, $80 \%$ ). TLC $\mathrm{R}_{f}=0.42$ (4:1 hexanes/EtOAc); ${ }^{1} \mathrm{H}$ NMR $\left(\mathrm{CDCl}_{3}, 400 \mathrm{MHz}\right) \delta 7.90-7.87(\mathrm{~m}, 2 \mathrm{H})$, 7.83-7.81 (m, 2H), 7.69-7.65 (m, 1H), 7.55-7.51 (m, 2H), 7.08-7.05 (m, 2H), 2.55 (s, 3H) ppm.

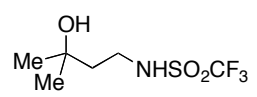

1,1,1-Trifluoro- $N$-(3-hydroxy-3-methylbutyl)methanesulfonamide (Table 2, Product 3). ${ }^{21 \mathrm{c}}$ Purified by chromatography on silica gel using 25\% EtOAc/hexanes (pale yellow oil, 37\%). TLC $\mathrm{R}_{\mathrm{f}}=0.12(7: 1 \text { hexanes/EtOAc })^{1} \mathrm{H} \mathrm{NMR}\left(\mathrm{CDCl}_{3}, 400 \mathrm{MHz}\right) \delta 6.50(\mathrm{~s}, 1 \mathrm{H})$, $3.50(\mathrm{~m}, 2 \mathrm{H}), 1.79-1.74(\mathrm{~m}, 2 \mathrm{H}), 1.66(\mathrm{~s}, 1 \mathrm{H}), 1.31(\mathrm{~s}, 6 \mathrm{H}) \mathrm{ppm}$.

$$
\underset{\mathrm{H}_{3} \mathrm{C}}{\mathrm{H}} \stackrel{\mathrm{C} \mathrm{H}_{3}}{\sim} \underset{\mathrm{OSO}_{2} \mathrm{Me}}{2-H y}
$$

2-Hydroxy-2-methylpropyl methanesulfonate. (Table 2, Product 5)

Purified by chromatography on silica gel using $20 \%$ acetone/hexanes (yellow oil, $58 \mathrm{mg}$, 34\%). TLC $R_{f}=0.64\left(20: 1 \mathrm{CH}_{2} \mathrm{Cl}_{2} / \mathrm{MeOH}\right) ;{ }^{1} \mathrm{H} \mathrm{NMR}\left(\mathrm{CDCl}_{3}, 400 \mathrm{MHz}\right) \delta 4.06(\mathrm{~s}, 2 \mathrm{H})$, $3.07(\mathrm{~s}, 3 \mathrm{H}), 1.30(\mathrm{~s}, 6 \mathrm{H}) \mathrm{ppm} ;{ }^{13} \mathrm{C} \mathrm{NMR}\left(\mathrm{CDCl}_{3}, 100 \mathrm{MHz}\right) \delta 76.8,69.8,37.7,26.0$ ppm; IR (thin film) $v 3425,3027,2935,1732,1491,1353,1174,966,920 \mathrm{~cm}^{-1}$.

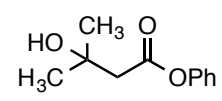

Phenyl 3-hydroxy-3-methylbutanoate. (Table S2, Product 6)

Purified by chromatography on silica gel using 15\% acetone/hexanes (clear oil, 38mg, $20 \%)$. TLC $R_{f}=0.56\left(6: 1\right.$ hexanes/acetone); ${ }^{1} \mathrm{H}$ NMR $\left(\mathrm{CDCl}_{3}, 400 \mathrm{MHz}\right) \delta 7.40(\mathrm{dd}, 2 \mathrm{H}$, $J=9.2,7.6 \mathrm{~Hz}$ ), 7.28-7.23 (m, 1H), 7.11-7.08 (m, 2H), 3.27 (s, 1H), 2.77 (s, 2H), 1.39 (s, 6H) ppm; ${ }^{13} \mathrm{C}$ NMR $\left(\mathrm{CDCl}_{3}, 100 \mathrm{MHz}\right) \delta 171.6,150.3,129.7,126.3,121.7,69.4,46.6$, 29.4 ppm; IR (thin film) v 3438, 2975, 2934, 1750, 1493, 1457, 1480, 1192, 1162, 1105 $\mathrm{cm}^{-1}$. HRMS $\left(\mathrm{ES}^{+}\right)$calcd for $\mathrm{C}_{11} \mathrm{H}_{14} \mathrm{O}_{3} \mathrm{Na}^{+} 217.0841$ found $217.0837\left[\mathrm{MNa}^{+}\right]$. 


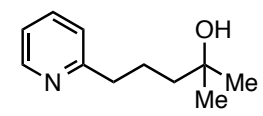

2-Methyl-5-(pyridin-2-yl)pentan-2-ol. (Table 4, Product 1)

Purified by chromatography on silica gel using $2.5 \% \mathrm{MeOH} / \mathrm{CH}_{2} \mathrm{Cl}_{2}$ (yellow oil, $59 \mathrm{mg}$, $66 \%)$. TLC $R_{f}=0.36\left(19: 1 \mathrm{CH}_{2} \mathrm{Cl}_{2} / \mathrm{MeOH}\right) ;{ }^{1} \mathrm{H} \mathrm{NMR}\left(\mathrm{CDCl}_{3}, 400 \mathrm{MHz}\right) \delta 8.58-8.43(\mathrm{~m}$, 1H), $7.60(\mathrm{td}, 1 \mathrm{H}, J=7.6,1.9 \mathrm{~Hz}), 7.19-7.05(\mathrm{~m}, 2 \mathrm{H}), 2.80(\mathrm{t}, 2 \mathrm{H}, J=7.6 \mathrm{~Hz}), 1.89-1.70$ $(\mathrm{m}, 2 \mathrm{H}), 1.61-1.43(\mathrm{~m}, 2 \mathrm{H}), 1.20(\mathrm{~s}, 6 \mathrm{H}) ;{ }^{13} \mathrm{C} \mathrm{NMR}\left(\mathrm{CDCl}_{3}, 100 \mathrm{MHz}\right) \delta 161.9,148.9$, $136.8,123.1,121.3,70.9,43.2,38.3,29.4,24.7$ ppm; IR (thin film) v 3371, 2967, 2359, $1717,1593,1436,1150 \mathrm{~cm}^{-1}$; HRMS $\left(\mathrm{ES}^{+}\right)$calcd for $\mathrm{C}_{11} \mathrm{H}_{18} \mathrm{NO}^{+} 180.1384$ found $180.1393\left[\mathrm{MH}^{+}\right]$.

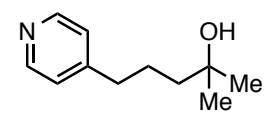

2-Methyl-5-(pyridin-4-yl)pentan-2-ol. (Table 4, Product 2)

Purified by chromatography on silica gel using $2.5 \% \mathrm{MeOH} / \mathrm{CH}_{2} \mathrm{Cl}_{2}$ (yellow oil, $45 \mathrm{mg}$, $50 \%)$. TLC $R_{f}=0.36\left(19: 1 \mathrm{CH}_{2} \mathrm{Cl}_{2} / \mathrm{MeOH}\right) ;{ }^{1} \mathrm{H} \mathrm{NMR}\left(\mathrm{CDCl}_{3}, 400 \mathrm{MHz}\right) \delta 8.56-8.35(\mathrm{~m}$, 2H), 7.21-7.01 (m, 2H), $2.62(\mathrm{t}, 2 \mathrm{H}, J=7.6 \mathrm{~Hz}), 2.14$ (br s, 1H), 1.79-1.64 (m, 2H), 1.55$1.43(\mathrm{~m}, 2 \mathrm{H}), 1.21(\mathrm{~s}, 6 \mathrm{H}) \mathrm{ppm} ;{ }^{13} \mathrm{C} \mathrm{NMR}\left(\mathrm{CDCl}_{3}, 100 \mathrm{MHz}\right) \delta$ 151.6, 149.6, 124.0, 70.6, 43.3, 35.7, 29.4, 25.1 ppm; IR (thin film) v 3326, 2966, 2866, 1604, 1558, 1416, 1219 $\mathrm{cm}^{-1}$; HRMS $\left(\mathrm{ES}^{+}\right)$calcd for $\mathrm{C}_{11} \mathrm{H}_{18} \mathrm{NO}^{+} 180.1384$, found $180.1404\left[\mathrm{MH}^{+}\right]$.

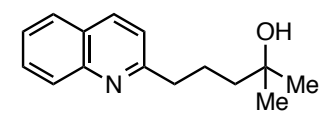

2-Methyl-5-(quinolin-2-yl)pentan-2-ol. (Table 4, Product 3)

Purified by chromatography on silica gel using 30\% acetone/hexanes (white solid, 49mg, $43 \%)$. TLC $R_{f}=0.38\left(19: 1 \mathrm{CH}_{2} \mathrm{Cl}_{2} / \mathrm{MeOH}\right) ;{ }^{1} \mathrm{H} \mathrm{NMR}\left(\mathrm{CDCl}_{3}, 400 \mathrm{MHz}\right) \delta 8.06(\mathrm{t}, 2 \mathrm{H}, J$ $=9.6 \mathrm{~Hz}), 7.79-7.76(\mathrm{~m}, 1 \mathrm{H}), 7.68(\mathrm{ddd}, 1 \mathrm{H}, J=8.4,7.0,1.4 \mathrm{~Hz}), 7.50-7.48(\mathrm{~m}, 1 \mathrm{H})$, $7.30(\mathrm{~d}, 1 \mathrm{H}, J=8.4 \mathrm{~Hz}), 3.01(\mathrm{t}, 2 \mathrm{H}, J=7.6 \mathrm{~Hz}), 2.94-1.90(\mathrm{~m}, 2 \mathrm{H}), 1.61-1.57(\mathrm{~m}, 2 \mathrm{H})$, 
$1.22(\mathrm{~s}, 6 \mathrm{H}) \mathrm{ppm} ;{ }^{13} \mathrm{C} \mathrm{NMR}\left(\mathrm{CDCl}_{3}, 100 \mathrm{MHz}\right) \delta 162.6,147.8,136.5,129.6,128.7$, 127.6, 126.8, 125.9, 121.6, 71.0, 43.2, 39.1, 29.5, 24.4 ppm; IR (thin film) v 3381, 3058, $2965,1711,1618,1600,1563,1504,827 \mathrm{~cm}^{-1}$. HRMS $\left(\mathrm{ES}^{+}\right)$calcd for $\mathrm{C}_{15} \mathrm{H}_{20} \mathrm{NO}^{+}$ 230.1545 found $230.1539\left[\mathrm{MH}^{+}\right]$.

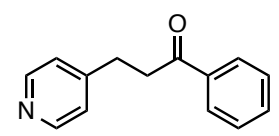

1-Phenyl-3-(pyridin-4-yl)propan-1-one. (Table 4, Product 4)

Purified by chromatography on silica gel using $20 \%$ acetone/hexanes (white solid, $63 \mathrm{mg}$, $60 \%)$. TLC $R_{f}=0.62\left(19: 1 \mathrm{CH}_{2} \mathrm{Cl}_{2} / \mathrm{MeOH}\right) ;{ }^{1} \mathrm{H} \mathrm{NMR}\left(\mathrm{CDCl}_{3}, 400 \mathrm{MHz}\right) \delta 8.50(\mathrm{~d}, 2 \mathrm{H}$, $J=6.0 \mathrm{~Hz}), 7.95(\mathrm{~d}, 2 \mathrm{H}, J=7.2 \mathrm{~Hz}), 7.57(\mathrm{t}, 1 \mathrm{H}, J=7.4 \mathrm{~Hz}), 7.48-7.44(\mathrm{~m}, 2 \mathrm{H}), 7.18(\mathrm{~d}$, $2 \mathrm{H}, J=6.0 \mathrm{~Hz}), 3.33(\mathrm{t}, 2 \mathrm{H}, J=7.4 \mathrm{~Hz}), 3.07(\mathrm{t}, 2 \mathrm{H}, J=7.4 \mathrm{~Hz}) \mathrm{ppm} ;{ }^{13} \mathrm{C} \mathrm{NMR}\left(\mathrm{CDCl}_{3}\right.$, $100 \mathrm{MHz}$ ) $\delta 198.7,150.7,150.3,137.0,133.8,129.1,128.4,124.3,39.3$, 29.6; IR (thin film) $v 3583,2956,2359,1712,1683,1579,1448,1414,1219 \mathrm{~cm}^{-1}$. HRMS $\left(\mathrm{ES}^{+}\right)$calcd for $\mathrm{C}_{14} \mathrm{H}_{14} \mathrm{NO}^{+} 212.1075$ found $212.1070\left[\mathrm{MH}^{+}\right]$.<smiles>CC(O)CCCOC(=O)c1ccncc1</smiles>

4-Hydroxy-4-methylpentyl isonicotinate. (Table 4, Product 5)

Purified by chromatography on silica gel using 50\% acetone/hexanes (white solid, $45 \mathrm{mg}$, 40\%). TLC $R_{f}=0.35\left(19: 1 \mathrm{CH}_{2} \mathrm{Cl}_{2} / \mathrm{MeOH}\right) ;{ }^{1} \mathrm{H} \mathrm{NMR}\left(\mathrm{CDCl}_{3}, 400 \mathrm{MHz}\right) \delta 8.79(\mathrm{dd}, 2 \mathrm{H}$, $J=4.6,1.4 \mathrm{~Hz}), 7.86(\mathrm{dd}, 2 \mathrm{H}, J=4.5,1.5 \mathrm{~Hz}), 4.39(\mathrm{t}, 2 \mathrm{H}, J=4.6,6.7 \mathrm{~Hz}), 1.94-1.87$ $(\mathrm{m}, 2 \mathrm{H}), 1.9(\mathrm{~s}, 1 \mathrm{H}), 1.64-1.60(\mathrm{~m}, 2 \mathrm{H}), 1.28(\mathrm{~s}, 6 \mathrm{H}) \mathrm{ppm} ;{ }^{13} \mathrm{C} \mathrm{NMR}\left(\mathrm{CDCl}_{3}, 100 \mathrm{MHz}\right) \delta$ 165.2, 150.7, 137.6, 123.0, 70.6, 66.3, 39.9, 29.5, 23.8 ppm; IR (thin film) v 3386, 2966, $1728,1408,1324,1284,1124 \mathrm{~cm}^{-1}$. 


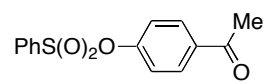

4-Acetylphenyl benzenesulfonate (Table 2, Product 2). ${ }^{21 \mathrm{c}}$

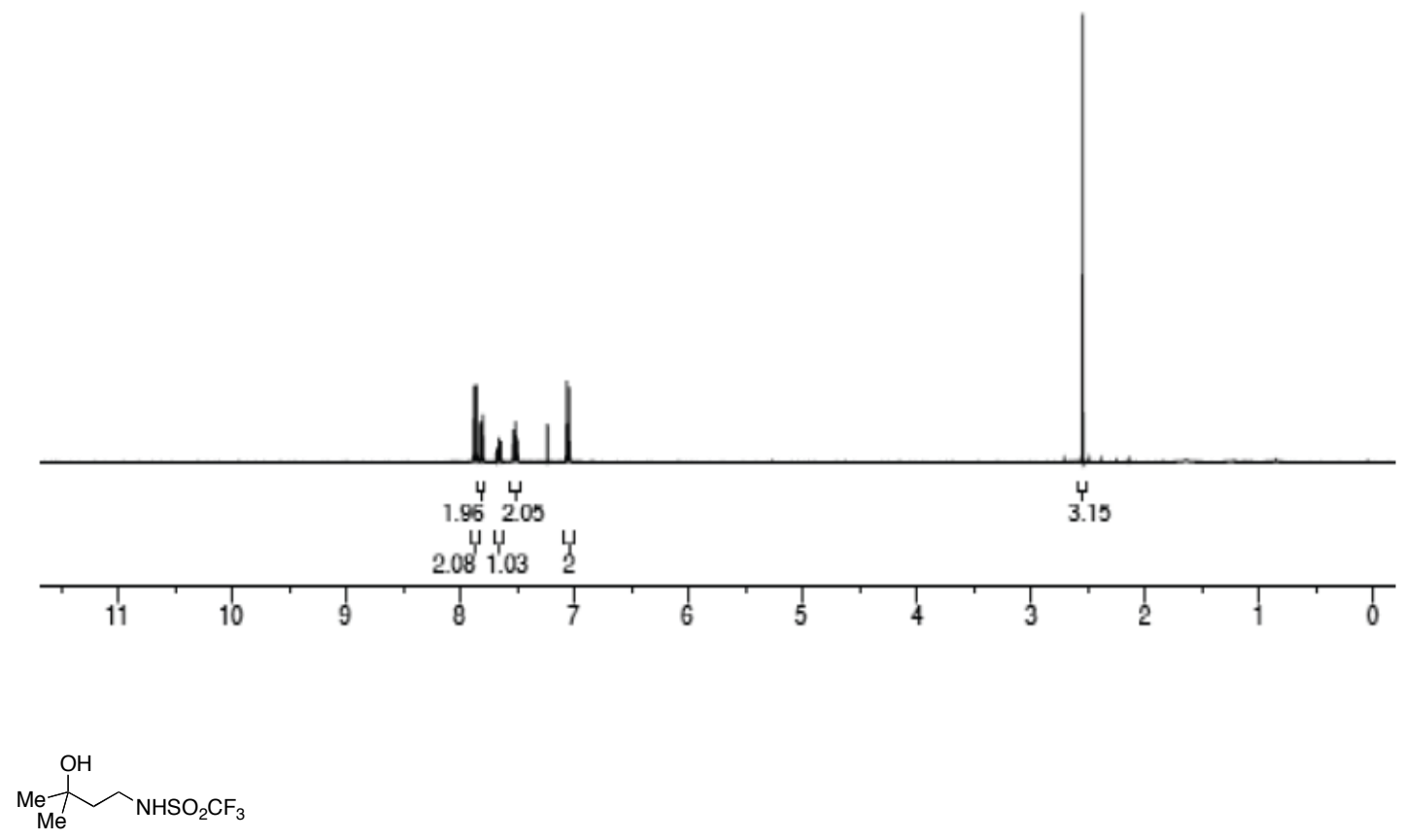

1,1,1-Trifluoro- $N$-(3-hydroxy-3-methylbutyl)methanesulfonamide (Table 2, Product 3). ${ }^{21 \mathrm{c}}$

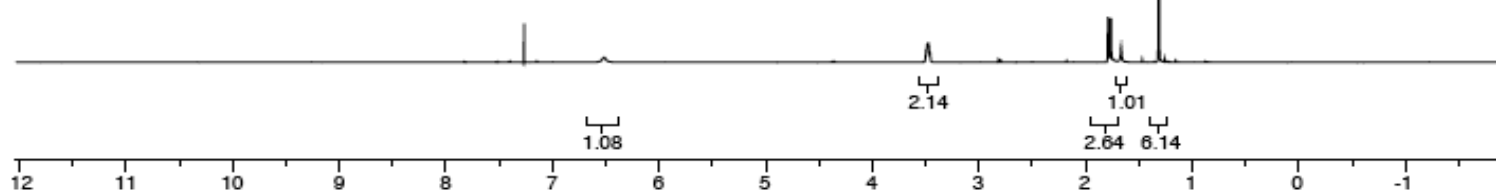




$$
\mathrm{HO}_{3} \mathrm{C} \stackrel{\mathrm{CH}_{3}}{\longrightarrow} \mathrm{OSO}_{2} \mathrm{Me}
$$

2-hydroxy-2-methylpropyl methanesulfonate. (Table 2, Product 5)
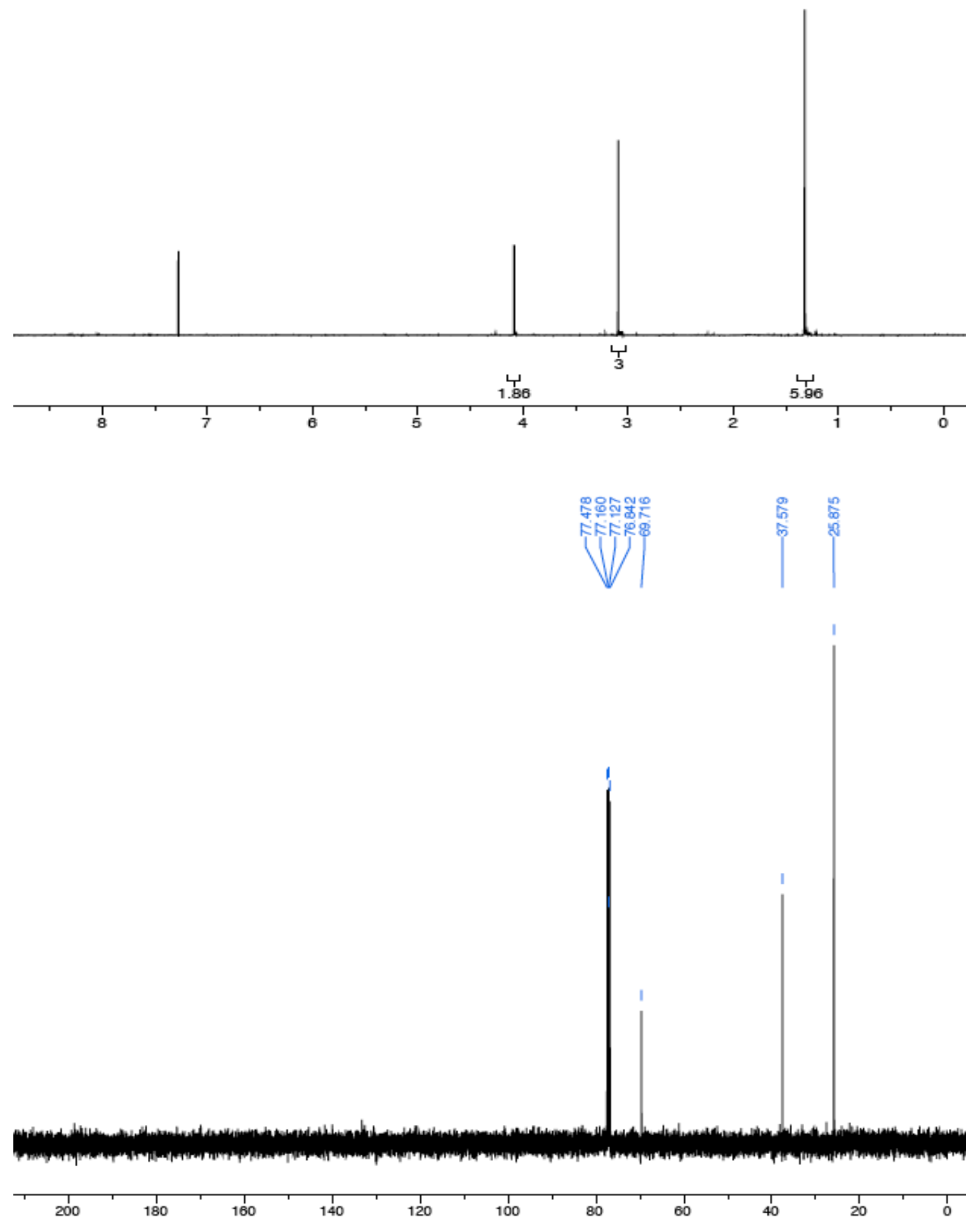


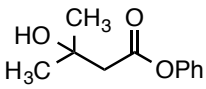

Phenyl 3-hydroxy-3-methylbutanoate. (Table S2, Product 6)

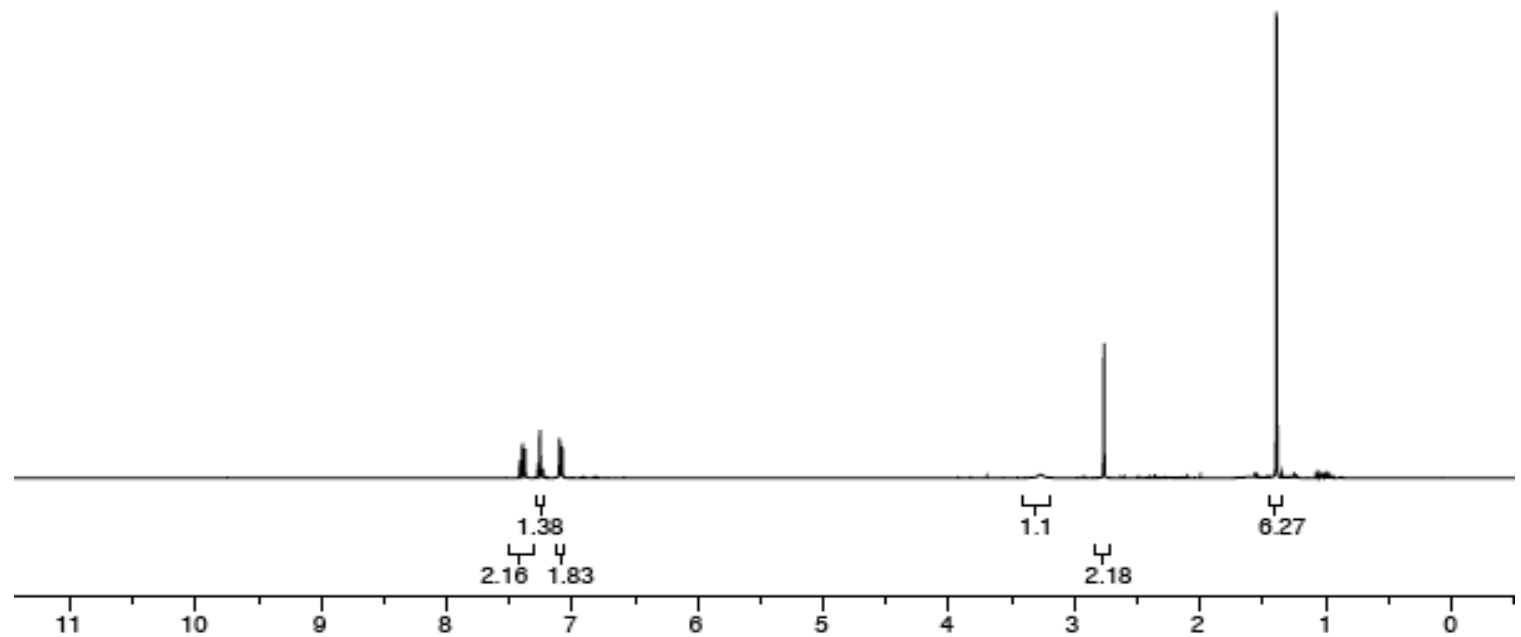

|

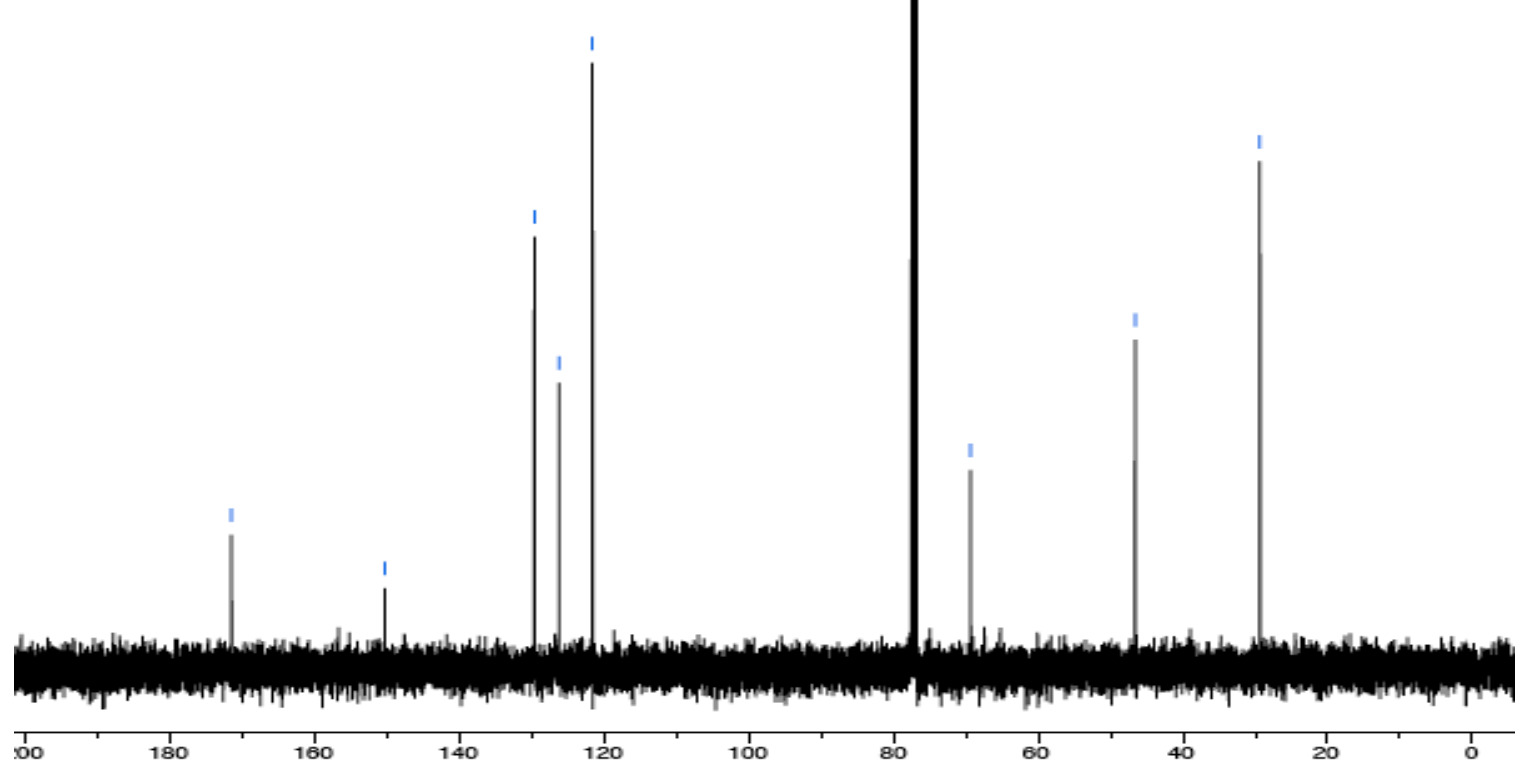




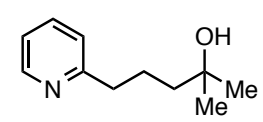

2-Methyl-5-(pyridin-2-yl)pentan-2-ol (Table 4, Product 1)
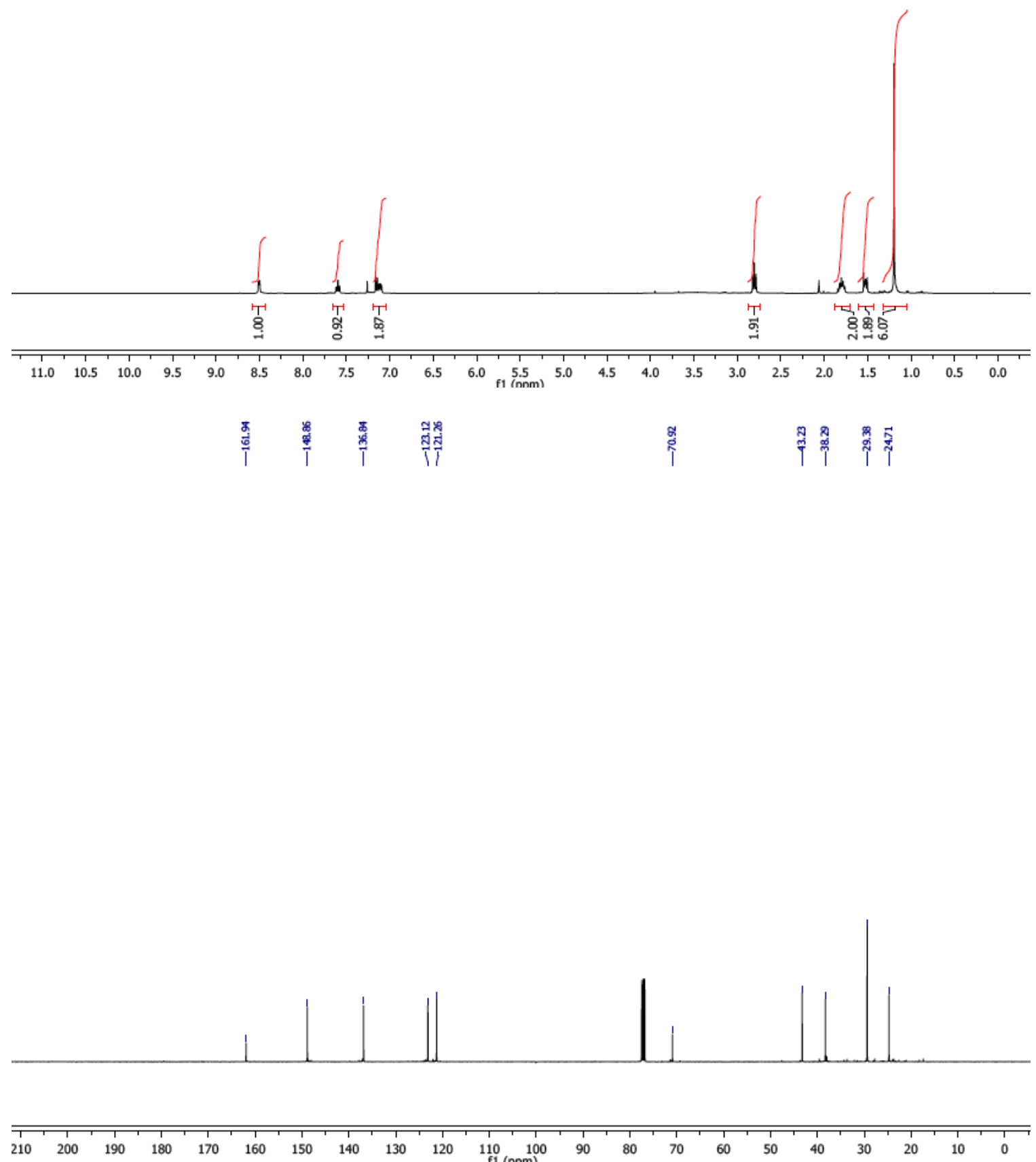


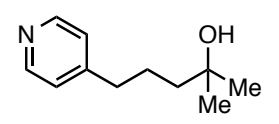

2-Methyl-5-(pyridin-4-yl)pentan-2-ol. (Table 4, Product 2)
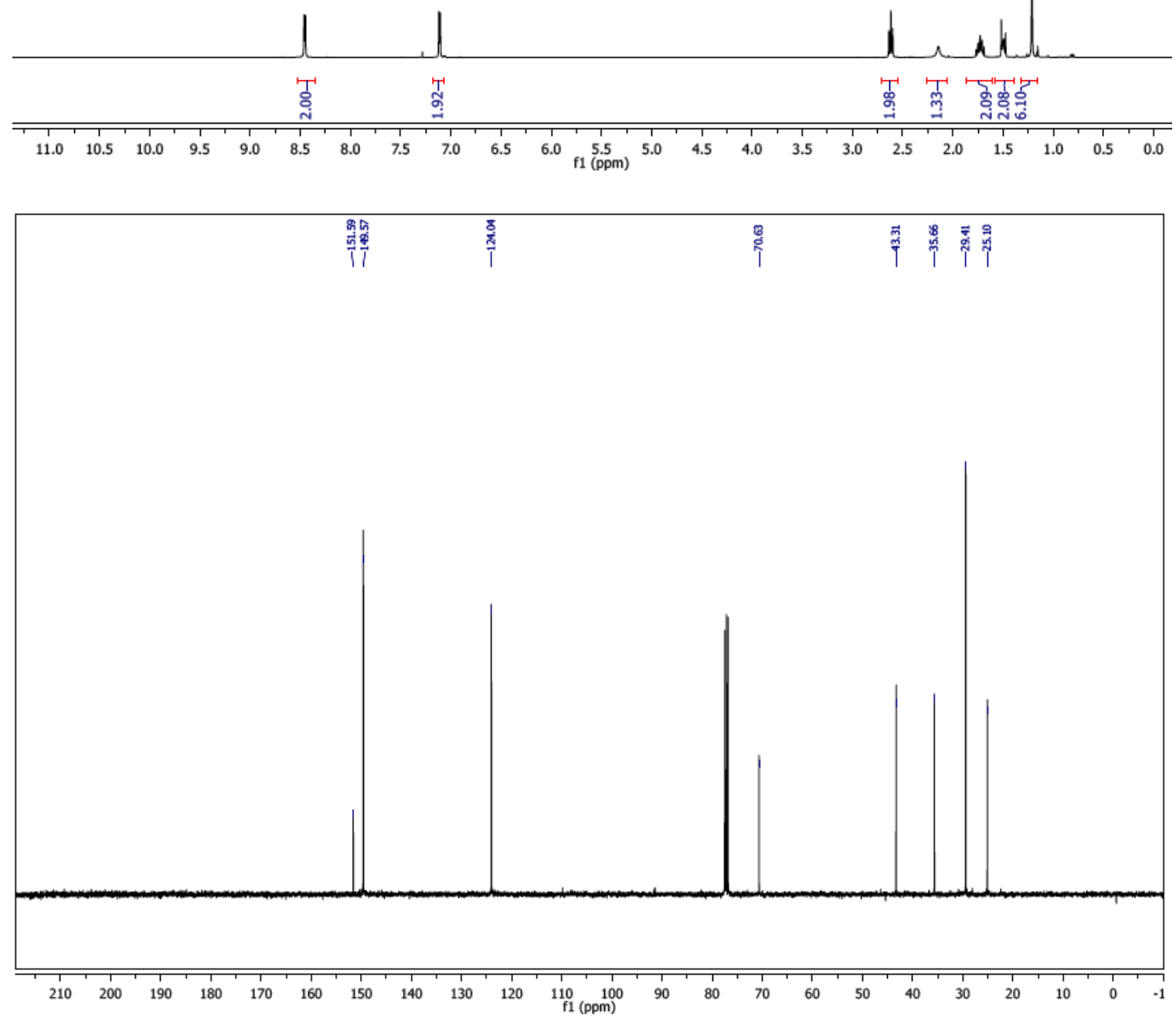


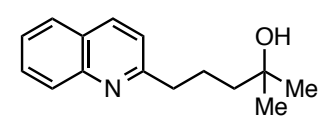

2-Methyl-5-(quinolin-2-yl)pentan-2-ol.(Table 4, Product 3)
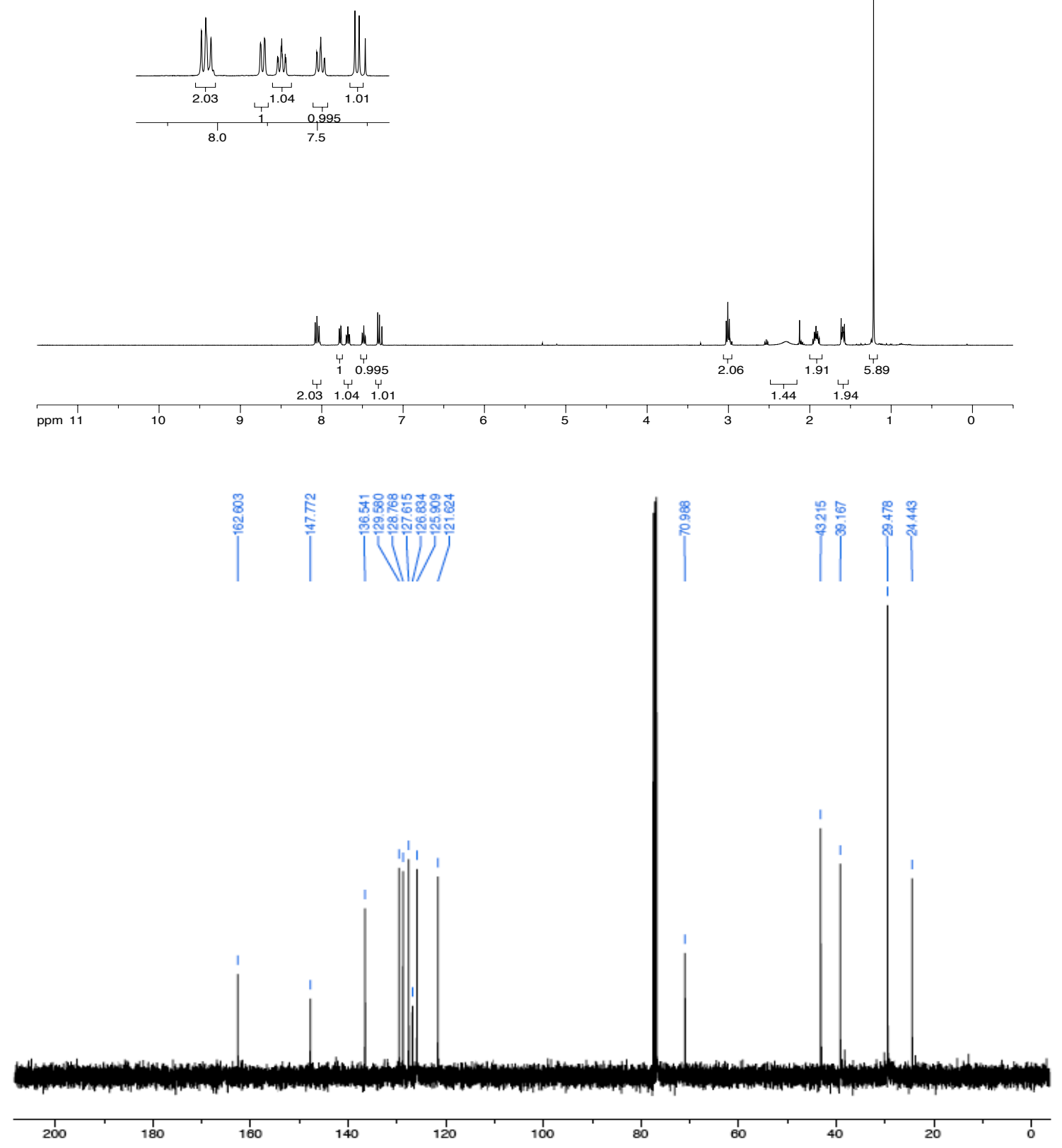


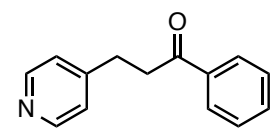

1-Phenyl-3-(pyridin-4-yl)propan-1-one. (Table 4, Product 4)
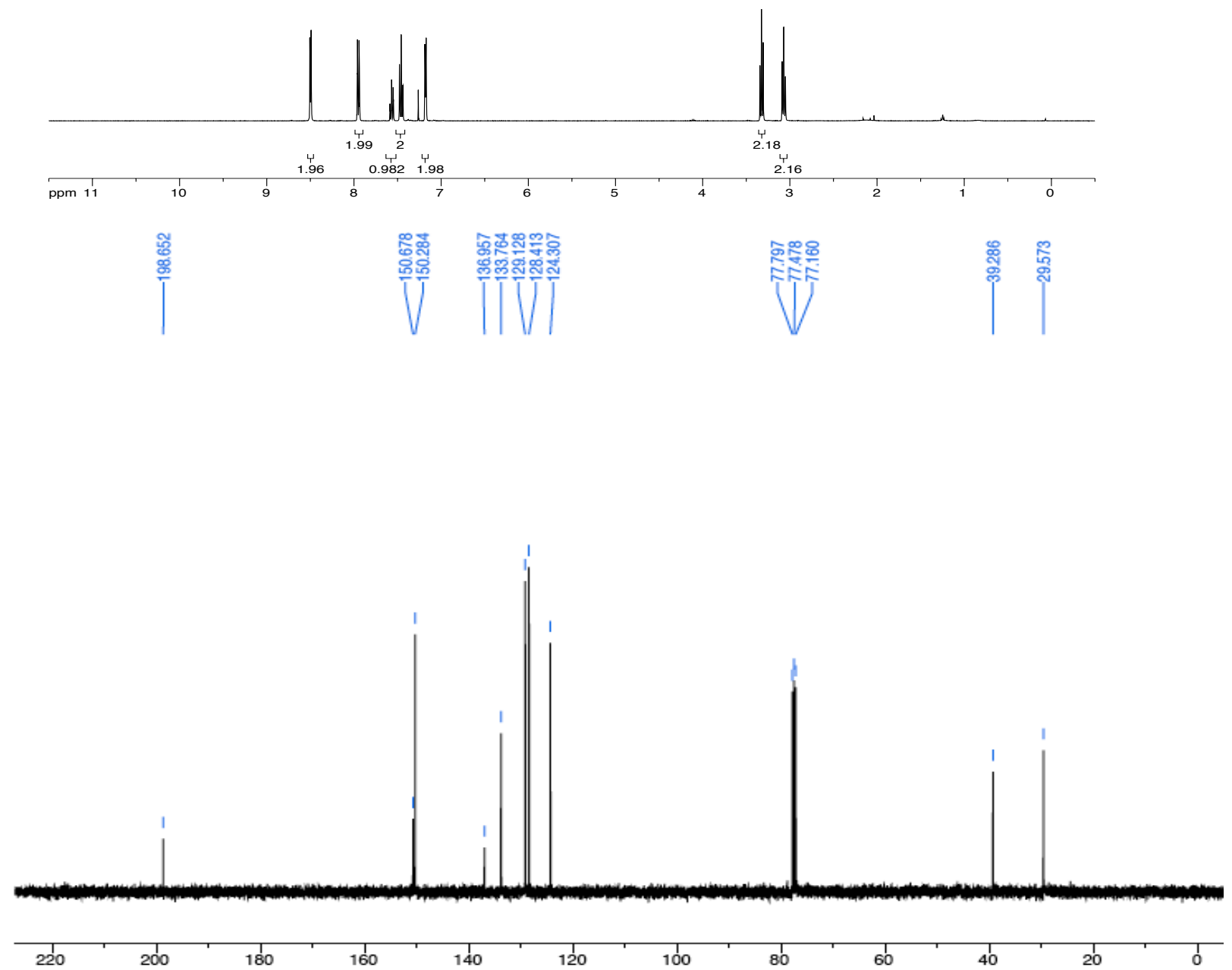


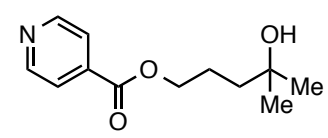

4-Hydroxy-4-methylpentyl isonicotinate. (Table 4, Product 5)
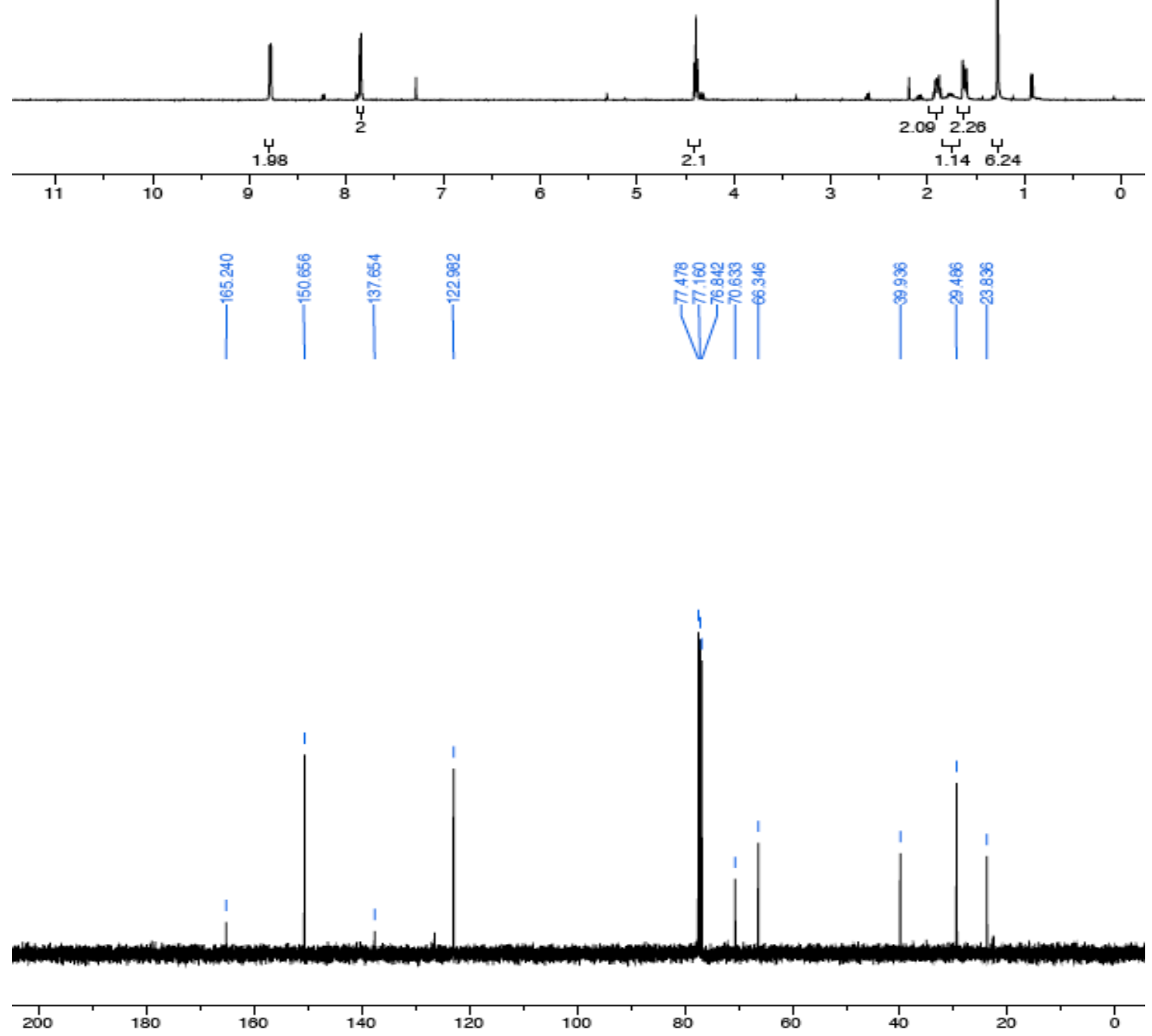